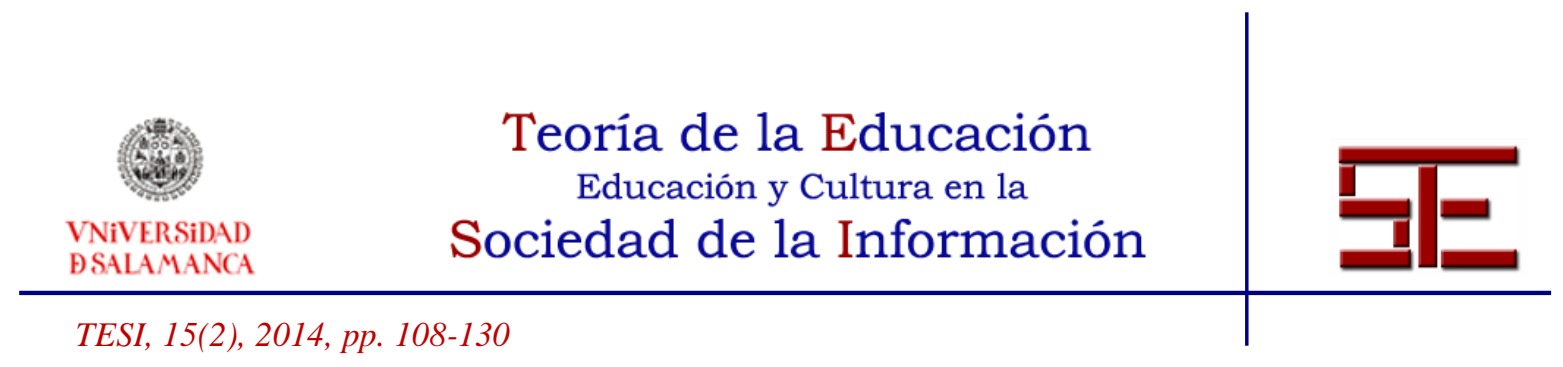

\title{
OBJETO DE APRENDIZAJE PARA LA FORMACIÓN DOCENTE ORIENTADO AL DESARROLLO DE COMPETENCIAS DE COMUNICACIÓN
}

Resumen: El presente artículo muestra los resultados y reflexiones obtenidos a través de la investigación que tuvo como objetivo analizar los criterios de calidad de un objeto de aprendizaje abierto encaminado a competencias para saber comunicarse y validar dichos objetos en función de su contenido, estructura pedagógica y tecnológica, lenguaje gráfico y textual y usabilidad para aportar a la formación de profesores, con el fin de llegar a fundamentar teórica, pedagógica y tecnológicamente un objeto de aprendizaje. Se partió de la interrogante: ¿Cuáles son los criterios de calidad que debe cubrir un objeto de aprendizaje (OA) orientado al desarrollo de competencias para saber comunicarse? Bajo un enfoque cuantitativo de tipo exploratorio, en el estudio se aplicaron cuestionarios electrónicos a 34 docentes de una Universidad Tecnológica y a ocho expertos en competencia comunicativa, pedagogía, tecnología y diseño gráfico. La información indicó que los criterios de calidad de un OA son el manejo efectivo del contenido de la competencia a aprender, la equilibrada composición de su estructura pedagógica, la eficiencia en la estructura tecnológica y el correcto manejo del lenguaje gráfico y textual.

Palabras clave: objeto de aprendizaje; competencias; comunicación; formación docente.

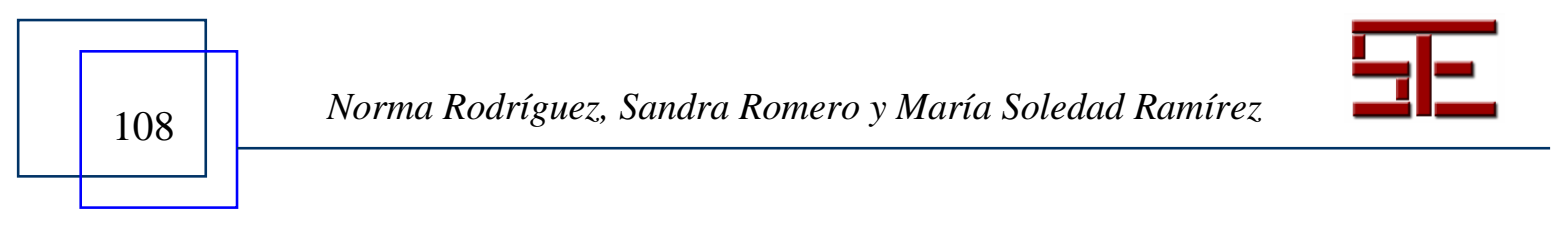




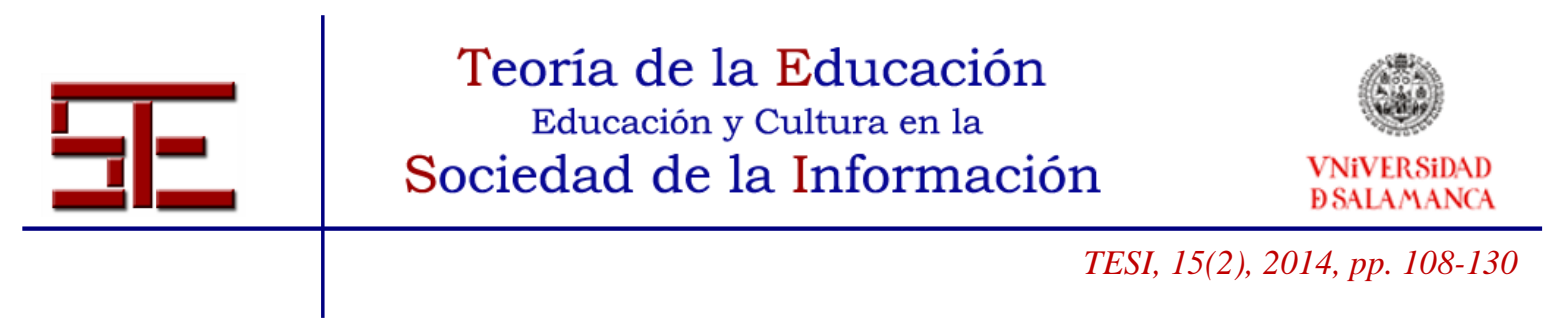

\title{
LEARNING OBJECT FOR TEACHER TRAINING AIMED TO DEVELOP COMMUNICATION SKILLS
}

\begin{abstract}
This article presents the results and reflections obtained across a research aimed to analyze the quality criteria of an opened learning object oriented to develop communication skills in order to be able to report and validate it according to its content, pedagogic structure, technological structure, graphical and textual language and usability to teacher training, in order to base it theoretically, pedagogically and technologically. The research question was: Which are the quality criteria that a learning object aimed to develop communication skills must cover? Under a quantitative approach, there were electronic questionnaires applied to: 34 Technological University teachers, eight experts about of communicative competence, teaching, technology and graphic design. The results indicated that some of the quality criteria of learning object are: the effective managing of the learning content, the balanced composition of his pedagogic structure, the technological structure efficiency and the proper managing of graphical and textual language.
\end{abstract}

Key words: learning object; competences; communication and teacher training.

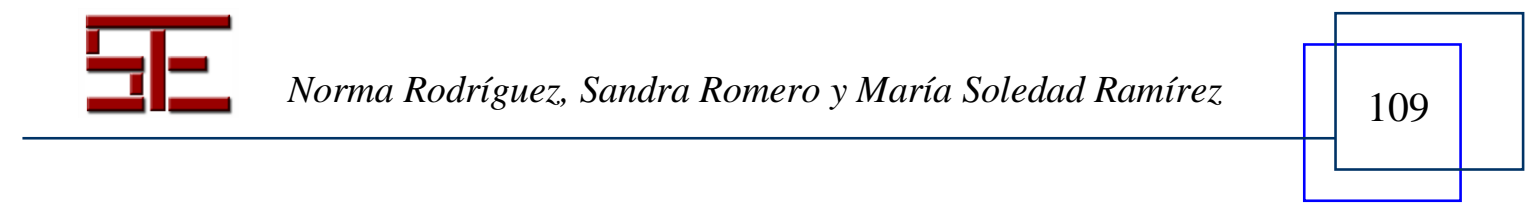




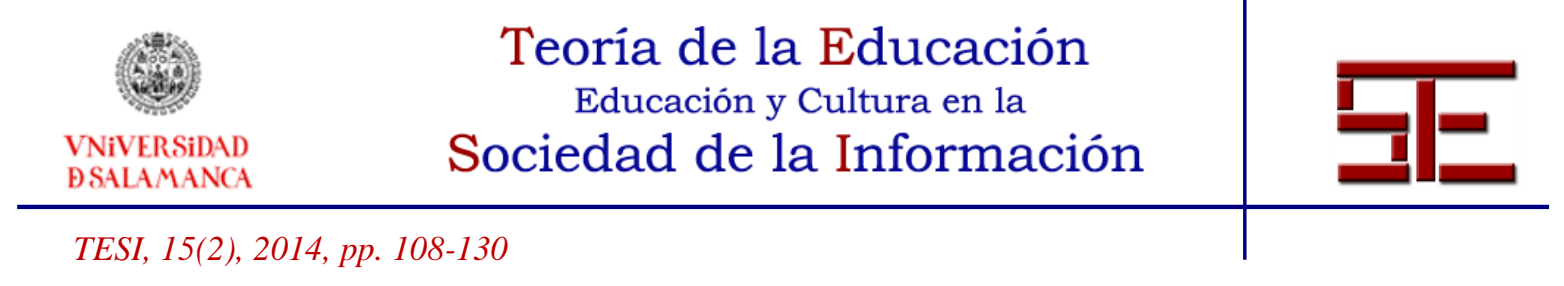

\section{OBJETO DE APRENDIZAJE PARA LA FORMACIÓN DOCENTE ORIENTADO AL DESARROLLO DE COMPETENCIAS DE COMUNICACIÓN}

Fecha de recepción: 13/02/2014; fecha de aceptación: 13/04/2014; fecha de publicación: 30/06/2014

Norma Esmeralda Rodríguez Ramírez

nerrodriguez@gmail.com

Universidad Tecnológica Fidel Velázquez

Sandra Irene Romero Corella

Instituto Tecnológico de Monterrey

Ma Soledad Ramírez

solramirez@tecvirtual.mx

Instituto Tecnológico de Monterrey

\section{1.- INTRODUCCIÓN}

El uso de la tecnología en la gestión del conocimiento ha favorecido los procesos educativos cuando se ha propiciado el acercamiento de información a aquellas comunidades donde es difícil tener acceso a la educación, además de generar nuevos ambientes de aprendizaje alternos a los ya establecidos. Sin embargo, la falta de infraestructura tecnológica y la formación de los facilitadores de procesos educativos pueden resultar barreras para que el uso de la tecnología tenga un impacto favorecedor en la promoción de la educación.

La presente investigación se circunscribe en el marco del macroproyecto "Evaluar para mejorar: Sistema de evaluación educativa para escuelas de bajo logro académico", el cual fue financiado por el Fondo Mixto de Fomento a la Investigación Científica y Tecnológica CONACYT - Gobierno del Estado de Tabasco (TAB - 2008 - C13 94053). En particular, este estudio se realizó en el contexto de una Universidad Tecnológica que pertenece al Subsistema de Universidades Tecnológicas, con 15 años de antigüedad. En dicha institución no se encontraron antecedentes que indiquen la formación docente para desarrollar material didáctico mediado por tecnología pese a ser una institución tecnológica cuya su misión es formar Técnicos Superiores Universitarios, capaces de desarrollar habilidades tecnológicas para que puedan incorporarse al sector productivo, es decir, debe haber un acercamiento directo con las nuevas tecnologías.

Los recursos con los que cuentan los docentes para impartir clases son elementales, pues van desde el pintarrón hasta el cañón de imagen, aunque este último es muy limitado en número, para poder cubrir las necesidades de todos los docentes.

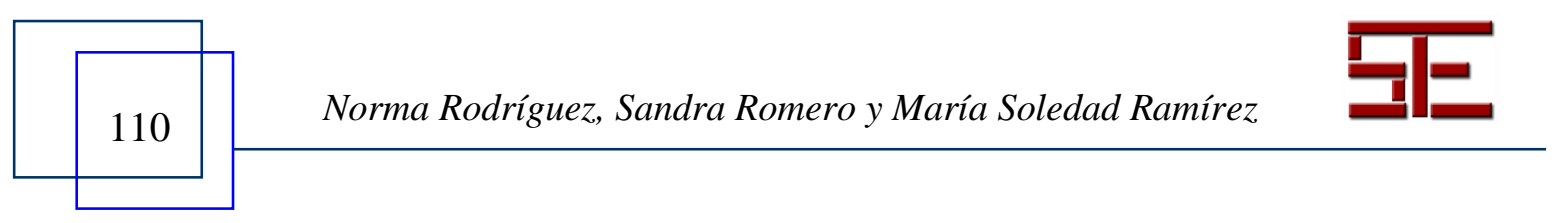




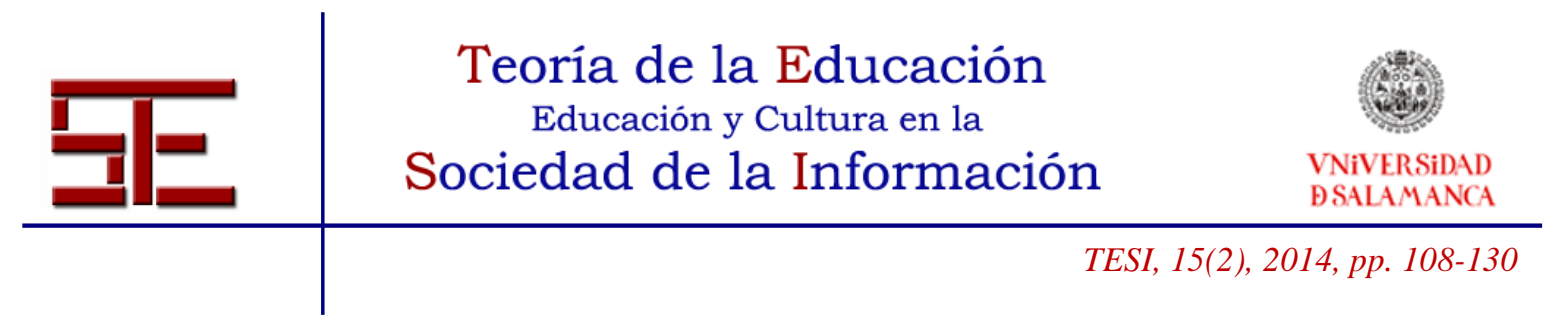

Además, por falta de presupuesto, la institución no ha invertido recursos económicos para mejorar la infraestructura tecnológica que propicie el desarrollo de estrategias didácticas ligadas a la innovación tecnológica como es el uso de los objetos de aprendizaje (OA).

De esta manera, en la institución se detectan necesidades de formación docente para que el facilitador pueda utilizar otro tipo de instrumentos tecnológicos como son los OA, que medien la comunicación con sus aprendices, además de producir la comunicación bidireccional y transversal, impulsando así el aprendizaje significativo.

Por otra parte, sería un error pensar que por el solo uso de las nuevas tecnologías en el aula se lograrán los objetivos de aprendizaje planteados, puesto que el resultado depende de cómo se organiza el mensaje y cómo se da a conocer, es decir, el desarrollo de competencias para saberse comunicar es imprescindible en la formación, puesto que es elemental que los profesores tengan la capacidad de saber qué estilos de comunicación son más propicios de acuerdo a las características de las personas que participan de los cursos, asimismo para identificar los diferentes estilos de aprendizaje de los alumnos con el propósito de adecuar el tipo de comunicación que se requiere para que tenga efecto el mensaje.

El poseer competencia comunicativa implica visualizar qué decir, a quién, cuándo, cómo decirlo y cuándo guardar silencio, es decir, va más allá de los conocimientos, experiencias y habilidades puesto que la comunicación soporta la motivación, sentido de pertenencia, adquisición de habilidades cognitivosinstrumentales. Esta habilidad en los actores educativos no se reduce únicamente a la parte lingüística, sino que tiene que ver con otros procesos como el uso adecuado de los instrumentos por los cuales se pretende enviar el mensaje, el dominio de un saber científico, de habilidades, procedimientos y técnicas que ayuden a realizar el proceso de comunicación en sus diferentes modalidades.

Desde esta perspectiva, surgió la inquietud de trabajar con recursos que fueran útiles para la formación docente y que a su vez apoyaran los procesos de comunicación, como elemento sustancial en el proceso educativo, fue así que se partió de la pregunta de investigación:

¿Cuáles son los criterios de calidad que debe cubrir un objeto de aprendizaje (OA) orientado al desarrollo de competencias para saber comunicarse?

Este artículo presenta el estudio que se desarrolló y parte de una descripción teórica donde se fundamentan los objetos de aprendizaje, las competencias comunicativas y estudios relacionados, posteriormente se presenta el marco metodológico que guio el estudio, así como los resultados, para concluir con hallazgos e implicaciones educativas. 


\section{Teoría de la Educación \\ Educación y Cultura en la \\ VNiVERSIDAD \\ DSALAMANCA \\ TESI, 15(2), 2014, pp. 108-130}

\section{2.- REFERENTE TEÓRICO}

El término objeto de aprendizaje (OA) fue acuñado en los años 70 en el área de Programación e Informática. Décadas después el Comité para la Normatividad de la Tecnología de Aprendizaje del Instituto de Ingenieros Eléctricos y Electrónicos designó como OA aquellos objetos digitales o no digitales que pueden ser utilizados, reutilizados o referenciados durante el aprendizaje apoyado con tecnología (Ramírez, 2006).

Sin embargo, otras concepciones puntualizan más el término, pues sólo lo aplican a la parte digital, por ejemplo, Wiley (2002) lo ubica como cualquier recurso digital que puede ser reutilizado como soporte para el aprendizaje. Al considerar que los OA son concebidos como entornos digitales (Akpinar, 2007) se tiene que pensar en el uso de lenguajes de programación, pues su diseño requiere de procedimientos como el análisis, construcción e implementación de códigos que permiten desarrollar los entornos digitales.

El OA al ser utilizado en la práctica educativa no sólo resulta ser un recurso digital innovador, sino un objeto mediático al ser "un conjunto de bits de texto, gráfico, videos o audio" (Chan, Galeana y Ramírez, 2006, 14) pues funge como enlace entre la tecnología y el aprendizaje significativo. Las autoras plantean también que cuando éste es visto como el mismo conocimiento por el sujeto, se convierte en un objeto de conocimiento y coinciden con Wiley (2002) al manifestar que, cuando hay un orden instruccional, al objeto mediático se le concibe como un nuevo tipo de elemento instruccional computarizado que surge del paradigma de modelamiento orientado a objetos (Ossandón y Castillo, 2006).

En la actualidad, se sugiere que los OA no sólo sean innovadores en cuanto a su diseño, sino también que sean capaces de producir conocimiento y generar competencias basadas en las necesidades del estudiante (Rodríguez y otros, 2013).

En América Latina, específicamente en México, la Comisión Académica de la Corporación Universitaria para el Desarrollo de Internet (CUDI) lo define como aquel recurso digital que se crea para la gestión del conocimiento al desempeñar una tarea, que tiene sentido en función de las necesidades del sujeto que lo usa y que representa y se corresponde con una realidad concreta susceptible de ser intervenida (Ramírez, 2007a). El aprendizaje que se busca y la contextualización de éste son incluidos por Leal y Tibaná (2006) cuando añaden que los OA deben estar constituidos por tres componentes internos: contenidos, actividades de aprendizaje y elementos de contextualización. En este mismo contexto, Ramírez, González, Lozano y Montalvo (2005) plantean que en el concepto de OA se fusionan la tecnología instruccional y las ciencias computacionales, puesto que de la primera se retoma la idea de que el aprendizaje está centrado en el alumno, a partir de estrategias constructivistas basadas en la solución de problemas. De la segunda se aplica el planteamiento: los componentes digitales pueden ser usados y reutilizados en diferentes entornos.

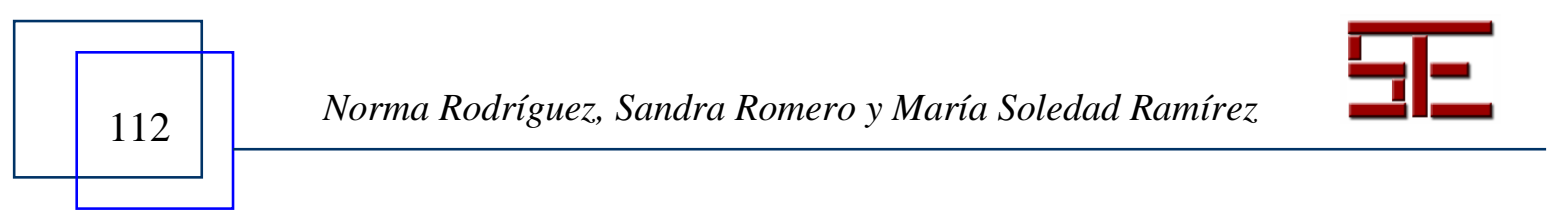




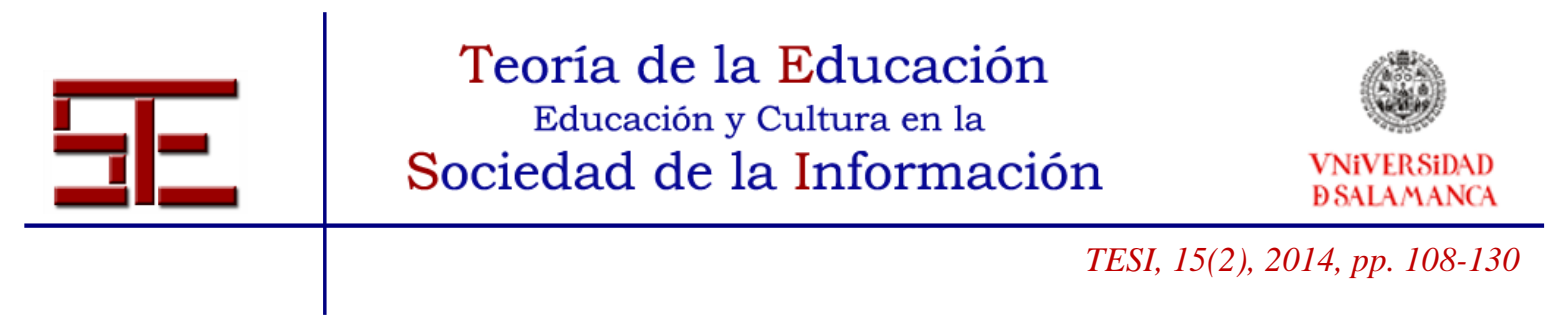

Para brindar más posibilidades de interacción entre los que participan de él, un OA debe de generar conocimiento y entendimiento más fructíferos (Hoodgins, 2002), por ello debe poseer características propias que lo hagan singular en comparación con otros recursos digitales. Aguilar, Moreno y Muñoz (2004) ubican tres características básicas: accesibilidad, reusabilidad/adaptabilidad e interoperabilidad.

Por otra parte, otras cualidades que son reconocidas por CUDI (Ramírez, 2007b) son: subjetividad, realidad, historicidad, complejidad, comunicabilidad, integrador, unidad coherente, unidades autocontenibles y versátiles, objetos reusables, capacidad de agrupación, clasificable, relevante, rico en recursos y agenda. Por tanto, un objeto de aprendizaje posibilita la construcción de saberes a partir de redes que se relacionan entre sí generando así pensamiento complejo (Morín, 2008).

Al respecto Hernández y Vázquez (2004) explican que la construcción del conocimiento se produce a través de la autonomía, del juicio y de la responsabilidad que las personas manifiestan al interactuar con su entorno aprovechando las posibilidades que ofrece la educación a lo largo de la vida. Otra de sus características es que puede ser reutilizado directamente o se puede combinar con otros objetos de aprendizaje utilizando la semántica entre los operadores de composición definidos (Amel, Defude, Duitama \& Lecocq, 2006). Es decir, hay unidad a través de árboles de conexión que les permiten dinamismo e interconexión, Ingo (2006) incluye, además, ir al metadato o árbol de archivos jerárquicos que se puede codificar fácilmente como un paquete de contenido IMS.

En cuanto a sus elementos, Chan, Galeana y Ramírez (2006) explican que un objeto de aprendizaje debe contener: prerrequisito(s), objetivo, actividad(es), recursos y evaluación. Las ventajas que ofrece son: la reusabilidad, el ahorro de tiempo y costos para el desarrollo de contenidos y, desde la perspectiva de distribución, un alto nivel de individualización, mecanismos robustos para actualización y envío de datos, y la estructuración y definición de recursos pedagógicos. Ello implica que los OA deben estar diseñados para facilitar la adquisición, evaluación y asimilación de contenidos mediante módulos de aprendizaje secuenciados (Chawla y Singla, 2010).

El aspecto de aprendizaje de los objetos de aprendizaje se refiere a la educación. Dado que la educación es un proceso, por lo que el objetivo principal de los objetos de aprendizaje tiende a facilitar la adquisición, evaluación y conversión de contenido en objetos de aprendizaje al tiempo que fomentan la asimilación de estos objetos de aprendizaje en módulos de aprendizaje y enseñanza.

Downes (2000) considera que, al tener estas cualidades, los OA permiten una educación flexible y personalizada con la relación profesor-alumno. A este tenor, algunos teóricos los catalogan como "medios de comunicación tangibles y métodos de instrucción (intangibles) que se utilizan para educar" (Escamilla, 1998, 15).

Especialistas como Aguilar, Moreno y Muñoz (2004), Wiley (2003), Argotte y otros (2009) y Churchill (2007) manifiestan que existen clasificaciones para los OA ya sea por el objetivo que persiguen, los recursos que utilizan o la información 


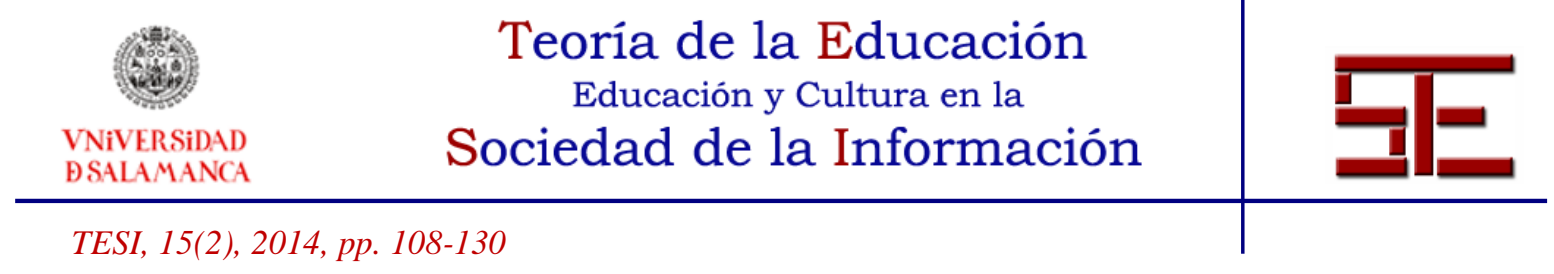

proporcionada por los metadatos ésta es la más concurrida por los docentes porque compagina los enfoques pedagógicos tradicionales a través de ordenadores al dar cuenta de un claro ejemplo de la fusión entre la tecnología y su apropiación por los docentes, ya que si la tecnología es utilizada apropiadamente tiene repercusiones sustanciales en el proceso de aprendizaje, la administración escolar y hasta la implementación de los proyectos en la educación (Banco Interamericano de Desarrollo, 2002), lo que significa que al usar la tecnología para la gestión del conocimiento no hay que perder de vista en qué ambientes y con qué fines es apropiada o no para el aprendizaje y la enseñanza (Bates y Poole, 2003).

A decir de Ogalde y González (2008), las TIC son herramientas que posibilitan de forma rápida y eficiente algunos procesos que van desde lo cotidiano como la comunicación, hasta algo más técnico como un cálculo o programa que automatice datos. Sin embargo, el proceso de asimilación e incorporación en el aula resulta complejo y difícil para el profesor, tal como lo mencionan Elizondo, Paredes y Prieto (2006) cuando declaran que existen instituciones que incorporan estos recursos, pero no aterrizan cómo y en qué actividades implementarlos.

Por tal razón, Hernández y Vázquez (2004) manifiestan la necesidad de un cambio actitudinal en las personas a la par que una modificación de políticas en las instituciones, especialmente en las educativas y en los gobiernos, pues las tecnologías por sí mismas no resuelven los problemas por los cuales se recurre a ellas, tal como lo señalan Celaya, Lozano y Ramírez (2009) al decir que la apropiación de tecnología no sólo transforma al usuario en conocimientos y habilidades, sino también modifica las propiedades de la tecnología.

En este sentido, la apropiación de la tecnología en la formación docente buscaría que se conocieran las tecnologías, se usaran y se modificaran para atender necesidades específicas de formación. En este sentido, Cázares y Cuevas (2007) manifiestan que una persona competente debe autogestionar el conocimiento que considere la comprensión; el saber hacer, como puesta en juego de habilidades basadas en los conocimientos; el saber ser, como la parte más compleja por sus implicaciones de carácter actitudinal e incluso valoral, y el saber transferir, como la posibilidad de trascender el contexto inmediato para actuar y adaptarse a nuevas situaciones o transformarlas. También explican que hay tres niveles en los que se deben desarrollar las competencias: el saber ser, saber conocer y saber hacer, sin perder de vista que las competencias pueden caducar o transformarse; por ello, Ramírez (2010) plantea que no solamente se trata de tener competencias, sino de tener también la capacidad para hablar de ellas, para evaluarlas, para adquirir otras nuevas y descartar las viejas.

En los nuevos escenarios correspondientes a las sociedades del siglo XXI, marcadas por el uso de las TIC, las instituciones educativas están optando por vincular las nuevas tecnologías con las nuevas formas de aprendizaje de la sociedad del conocimiento, donde la forma de comunicar los aprendizajes se ve manifestada en los intercambios de información que se van vinculando con las experiencias cotidianas

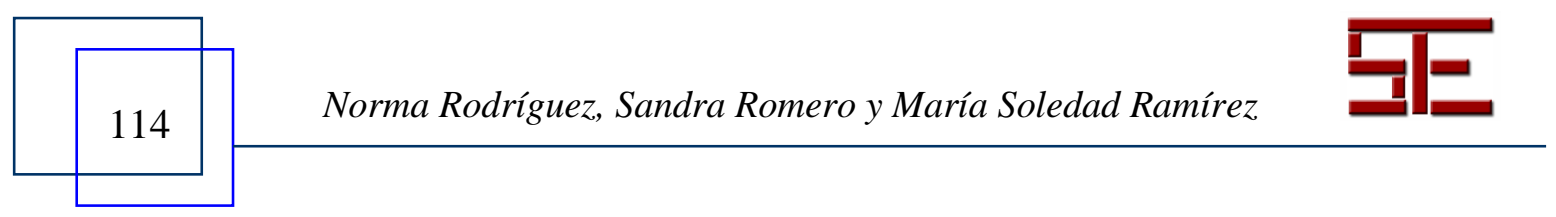




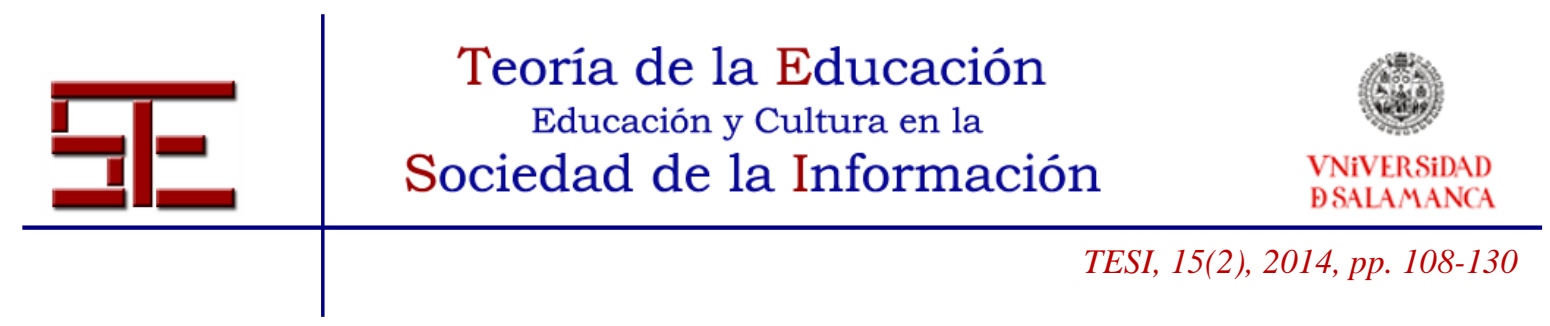

ubicadas en el tejido social, es decir, a partir de la convivencia se pueden generar nuevos aprendizajes y la capacidad de entenderse con alguien acerca de algo intercambiando roles para producir el significado dentro del mismo ámbito del uso (Tobón, 2006).

De la Rosa (2004) plantea que la comunicación enfocada a la docencia es la capacidad para la producción, recepción e interpretación de mensajes de diferentes tipos y a través de diferentes medios, que puedan promover interacciones educativas, a diferencia de otros procesos formativos o de entrenamiento para el uso de los medios que ponen énfasis en el dominio de los aparatos y sus potencialidades para la circulación y uso de mensajes producidos. En consecuencia resulta imperante desarrollar la comunicación eficaz como parte integrante del sistema de apoyo para mejorar el rendimiento profesional en las funciones de diseño instruccional, toda vez que ofrece mayores posibilidades para un discurso significativo entre los usuarios finales de la instrucción (Larbi \& Moseley, 2009).

En este momento, en la competencia comunicativa docente, es necesario que los roles de los maestros cambien, puesto que las formas de adquirir el conocimiento han variado como consecuencia del uso de las tecnologías, liberando al profesor de las tareas repetitivas, estrictamente informacionales (Tejada, 2002). Ahora se centra la atención en el dominio de la competencia comunicativa porque se utilizan entornos virtuales para intercambiar conocimientos y experiencias (Levinsen, 2007). Los nuevos papeles son: guía, facilitador, instructor, experto tecnológico, administrador, documentalista, evaluador, por mencionar los principales.

Además, es imprescindible, a través de estudios científicos, replantearse continuamente si las competencias docentes (en este caso, la comunicativa) van respondiendo a los cambios generados en las instituciones (Selvi, 2010) en cuestión de tecnología, ya que de acuerdo al estudio de Manny, y otros (2011) actualmente los profesores están en la etapa de adquisición de las competencias técnicas para el uso de recursos educativos mediados por la tecnología y esta actualización tiene el fin de enriquecer la pedagogía actual.

Por tanto: ¿Qué necesita el docente para desarrollar la competencia comunicativa? Fonseca (2002) recomienda lo siguiente: establecer qué, el porqué, quién lo va a escuchar, cómo, en qué momento y dónde. De no establecerse estos criterios se corre el riesgo de que no sea efectiva la comunicación (Faulkner, 2009).

Wesley y Richard (2009) aconsejan que el docente hable menos para que los estudiantes piensen más, que trate de no hablar más del $20 \%$ del tiempo de la clase. Que haga dinámica la sesión a través de discusiones o debates para que los estudiantes se hablen en grupos de dos o tres para resumir los datos claves, propiciando así la interacción.

Asimismo, Sánchez (2003) plantea que al incorporar las tecnologías de la información al aprendizaje es necesario que el docente se pregunte: ¿cuándo es 


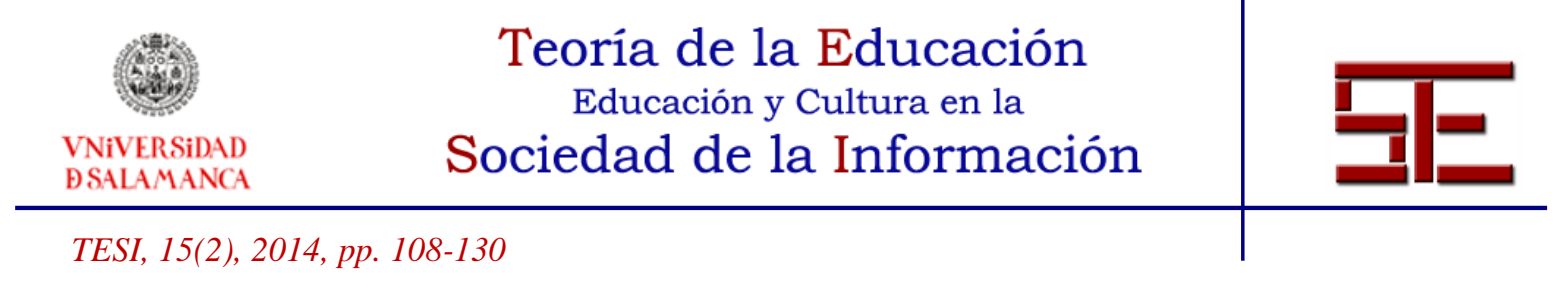

necesario diseñar material?, ¿cuáles criterios de calidad hay que tener en cuenta?, y ¿cuáles herramientas informáticas se deben utilizar?

El docente, a través de la comunicación, debe practicar la cultura de colaboración (Hargreaves, 2005) para que tenga la capacidad de emprender acciones didácticas con autonomía, apertura y espontaneidad que lo impulsen a la inventiva (Santiago, 2004) en su práctica en el aula para descubrir o redescubrir los conocimientos $\mathrm{y}$, con ello, estimular las iniciativas para emprender situaciones comunicativas efectivas ya que el uso de herramientas tecnológicas sin interacción colaborativa no garantiza la construcción del conocimiento (Noguera, 2013).

Actualmente, dentro de las herramientas tecnológicas que regularmente utiliza el docente al impartir la clase están: administrador de presentaciones, en los cuales se pueden utilizar recursos multimedia (Paz, 2007); Enciclomedia, definido por la Secretaría de Educación Pública (2009) como una herramienta educativa basada en la organización y administración de recursos que están soportados en libros de textos digitalizados; Aula Virtual, la cual se ubica en términos de lograr una comunicación visual y de voz entre localidades diferentes, con el fin de compartir, con un campus con limitaciones, recursos como maestros o cursos completos (Appana, 2008), por lo cual se requiere de docentes capaces de intervenir su contexto educativo inmediato (Abdón, 2003).

Algunas investigaciones realizadas sobre los $\mathrm{OA}$ indican que su producción (Rivera, Lozano y Ramírez, 2008), diseño instruccional (Jessup, 2007) y utilización determinan que si bien es cierto que los objetos de aprendizaje por los recursos y bondades que ofrecen se han utilizado con fines de capacitación docente, aún no se ha considerado la posibilidad de utilizarlos para desarrollar competencias comunicativas (Looser, 2005).

\section{3.- MARCO METODOLÓGICO}

La metodología del estudio fue de tipo exploratorio con docentes (seleccionados intencionalmente de acuerdo con ciertas características homogéneas pre establecidas) y validación de expertos (seleccionados intencionalmente por su área disciplinar). Se partió de la producción de un OA de un área específica de formación (competencia comunicativa) y se validó con expertos y docentes a través de la aplicación de cuestionarios autoadministrados.

Las categorías exploradas a través de los cuestionarios fueron las siguientes: (a) contenido de la competencia a aprender (relevancia y alcance), (b) estructura pedagógica (objetivos, motivación y evaluación), (c) estructura tecnológica (usabilidad, accesabilidad y reusabilidad) y (d) lenguaje gráfico y textual (sintáxis gráfica y semántica del OA). Tal como lo muestran las Tablas 1, 2, 3 y 4.

Tabla 1

Cuestionario sobre la competencia a aprender con el objeto

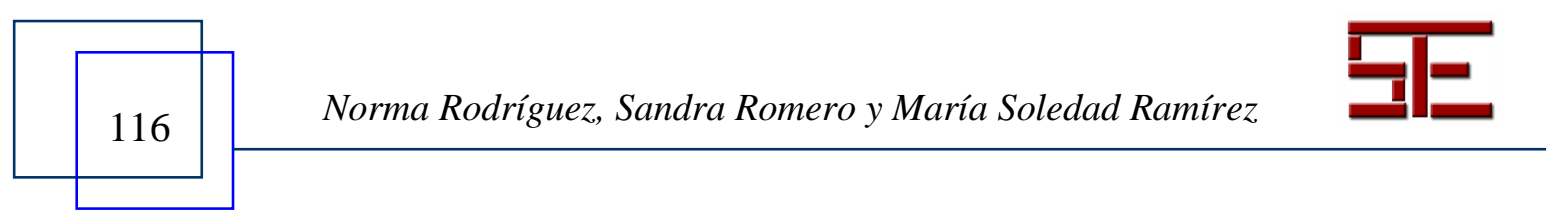




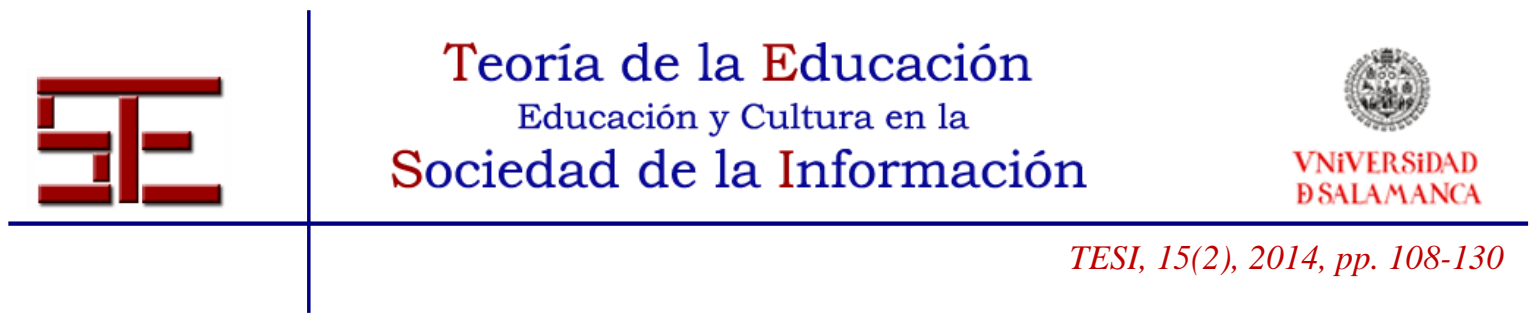

\begin{tabular}{lll}
\hline Categoría & Indicadores & Preguntas \\
\hline $\begin{array}{l}\text { Competencia a } \\
\text { aprender con el Objeto } \\
\text { de Aprendizaje }\end{array}$ & $\begin{array}{l}\text { 1. A través del Objeto de Aprendizaje (OA) se crea } \\
\text { una conceptualización de la competencia desde una } \\
\text { perspectiva teórica. } \\
\text { 2. La competencia que se promueve es importante en } \\
\text { el contexto de una sociedad basada en el conocimiento. }\end{array}$ \\
& $\begin{array}{l}\text { 1. Se logra el desarrollo de la competencia en el } \\
\text { docente. }\end{array}$ \\
& $\begin{array}{l}\text { Alcances } \\
\text { habilidades por parte del docente para enseñar la } \\
\text { competencia a los alumnos. } \\
\text { 3. Se mencionan elementos acerca de cómo aprende el } \\
\text { alumno la competencia. } \\
\text { 4. Se presentan estrategias de evaluación del desarrollo } \\
\text { de la competencia en los alumnos implícitas en el OA. }\end{array}$ \\
\end{tabular}

Tabla 2

Cuestionario sobre la estructura pedagógica del objeto

\begin{tabular}{|c|c|c|}
\hline Categoría & Indicadores & Preguntas \\
\hline \multirow[t]{3}{*}{$\begin{array}{l}\text { Estructura } \\
\text { del Objeto }\end{array}$} & Objetivos de aprendizaje & $\begin{array}{l}\text { 1. Los objetivos de aprendizaje se definen con } \\
\text { claridad. } \\
\text { 2. Los objetivos de aprendizaje son adecuados para las } \\
\text { intenciones didácticas. } \\
\text { 3. El logro de los objetivos aporta a la construcción del } \\
\text { conocimiento. } \\
\text { 4. Los objetivos fomentan el aprendizaje significativo. } \\
\text { 5. Los objetivos se apoyan en instrucciones caras para } \\
\text { la utilización del OA. }\end{array}$ \\
\hline & Motivación & $\begin{array}{l}\text { 1. El Objeto de Aprendizaje es altamente motivador } \\
\text { 2. Con el OA se estimula el interés del alumno a través } \\
\text { de simulaciones basadas en la realidad. } \\
\text { 3. Los elementos multimedia del OA contribuyen } \\
\text { eficazmente en la motivación. } \\
\text { 4. En el OA se presentan retos intelectuales que atraen } \\
\text { la atención del usuario. } \\
\text { 5. La estrategia de enseñanza utilizada en el OA } \\
\text { promueve el aprendizaje. }\end{array}$ \\
\hline & Evaluación & $\begin{array}{l}\text { 1. La evaluación utilizada en el OA explora } \\
\text { conocimientos previos. }\end{array}$ \\
\hline
\end{tabular}

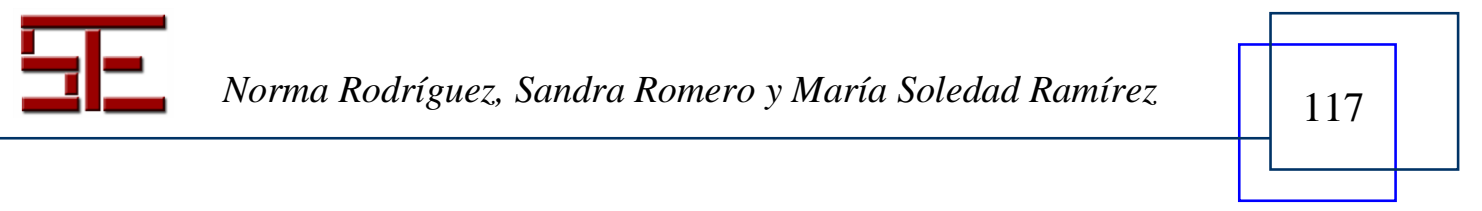




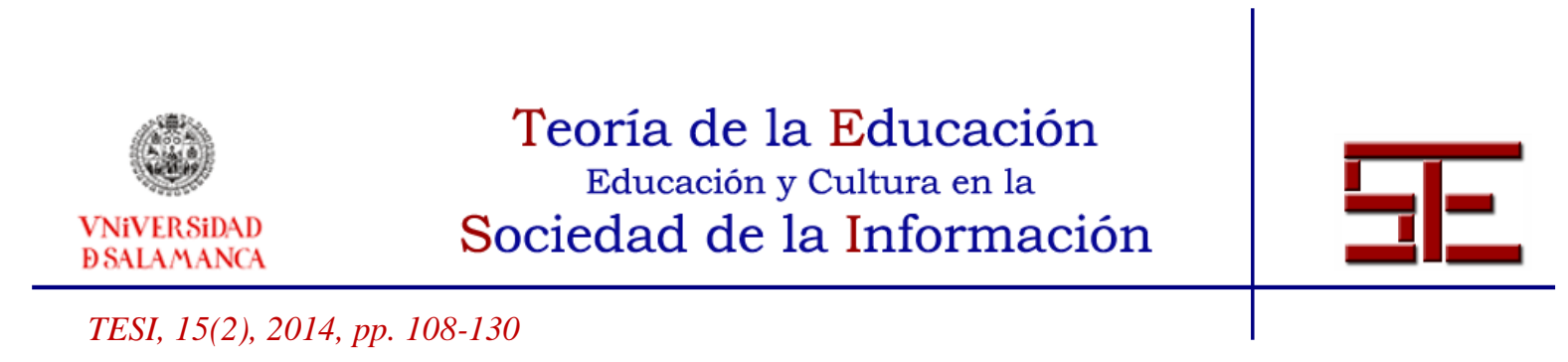

2. La evaluación utilizada en el OA explora los resultados de la adquisición de la competencia.

3. La evaluación utilizada en el OA proporciona información útil para retroalimentar los aprendizajes.

Tabla 3

Cuestionario sobre la estructura tecnológica del Objeto

\begin{tabular}{lll}
\hline Categoría & Indicadores & Preguntas \\
\hline Estructura & tecnológica & Usabilidad \\
del Objeto & 1. La navegación es amigable, se facilita navegar en el \\
& objeto. \\
& 2. La presentación de información en la interfaz es \\
& lógica para el usuario. \\
& 3. El contenido de los recursos es claro. \\
& 4. El contenido de los recursos es preciso. \\
& 5. El contenido de los recursos es pertinente. \\
& 6. EL contenido de los recursos es adecuado.
\end{tabular}

Accesibilidad

1. Se encontró fácil el acceso al portal.

2. El diseño de controles para manipular el objeto es adecuado.

3. Se incluyen elementos multimedia.

4. La información se puede adaptar a dispositivos móviles.

Reusabilidad

1. Puede ser comprendido por personas de diferente preparación.

2. Los recursos educativos no son muy pesados.

3. Se puede utilizar en varios escenarios.

4. Es evidente la pertinencia del diseño.

6. El Objeto de Aprendizaje cumple con los estándares internacionales conocidos.

7. Los metadatos que se proporcionan son los necesarios.

8. Los metadatos son visibles.

Tabla 4

Cuestionario sobre el lenguaje gráfico y textual del objeto

\begin{tabular}{lll}
\hline Categoría & Indicadores & Preguntas \\
\hline $\begin{array}{l}\text { Lenguaje gráfico } \\
\text { textual del objeto }\end{array}$ & Sintaxis gráfica & 1. La selección de la fuente para el Objeto de \\
& & Aprendizaje es adecuada. \\
& & 2. La tipografía es legible en el OA. \\
& 3. En el diseño del OA hay un adecuado contraste de \\
& &
\end{tabular}

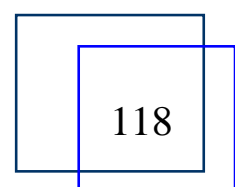

Norma Rodríguez, Sandra Romero y María Soledad Ramírez

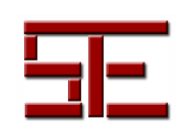




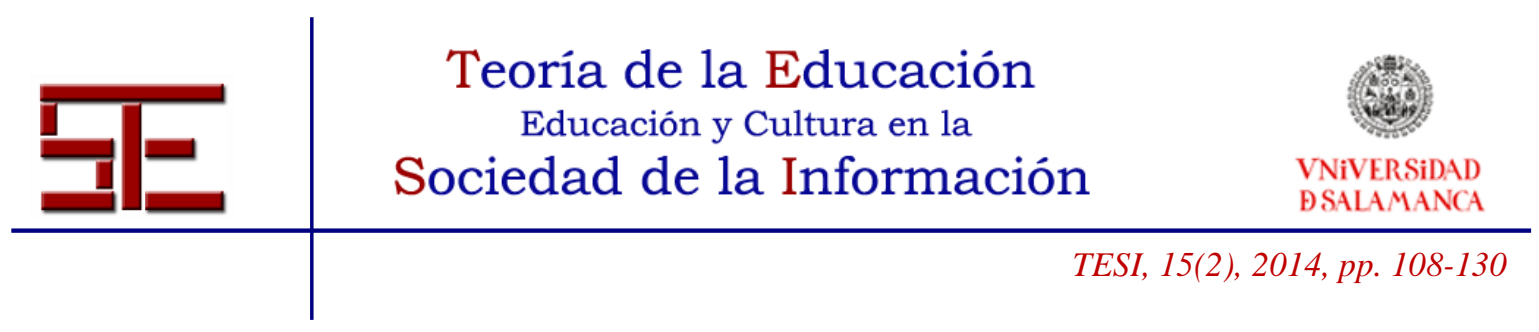

4. Existe homogeneidad en las imágenes.

5. La jerarquía visual de los elementos gráficos es adecuada.

Semántica del OA

1. El nivel lingüístico del Objeto de Aprendizaje es apropiado para los usuarios.

2. Hay coherencia interna del discurso en la estructura del texto.

3. La redacción es clara para promover la comprensión del tema por parte de los usuarios.

Se partió de tres etapas con el desarrollo de un OA de licenciamiento abierto, la validación de diversos especialistas y la aplicación en procesos de formación docente:

(1)Producción del objeto de aprendizaje de licenciamiento abierto.

El desarrollo del OA se produjo con el apoyo de distintos roles por parte de diversos profesionales:

(a) Autor de contenido, que fue el encargado de desarrollar los elementos pedagógicos, gráficos y conceptuales del OA; en los aspectos conceptuales se les solicitó dar respuesta a las interrogantes siguientes (en cada objeto por competencia): ¿cómo se conceptualiza la competencia?, ¿por qué es relevante esta competencia para una sociedad basada en conocimiento?, ¿cómo las personas desarrollan la competencia?, ¿cómo es posible enseñar esta competencia a los alumnos?, ¿cómo los alumnos aprenden la competencia? y ¿cómo el profesor puede evaluar si sus alumnos han desarrollado la competencia?

(b) Diseñador instruccional, que apoyó en las actividades siguientes: desarrollo de plantillas para diseño instruccional, asesoría y retroalimentación a los autores de contenido para generar el borrador con las principales ideas del OA, corrección del contenido de todo el objeto, en fondo y forma, para generar las versiones finales listas para pasárselas a los programadores, entrega de los objetos a los programadores y entrega de documentación con estándares para una eventual programación de los objetos con SCORM para documentar el OA.

(c) Programadores Web, para realizar el diseño gráfico general de la interfaz del objeto, diseñar una plantilla estándar para la programación del OA, hacer la programación del OA (incluido el diseño gráfico de las imágenes que pudieran requerirse), montar el OA en la página web del proyecto y en una sección de recursos educativos abiertos de la cátedra de investigación en Innovación en Tecnología y Educación.

El OA producido para este estudio fue el siguiente:

Rodríguez, N. E. (2010). Competencia saber comunicarse [objeto de aprendizaje]. Disponible en el sitio web: http://www.ruv.itesm.mx/convenio/tabasco/oas/sc/homedoc.htm. Disponible en el repositorio abierto de la Cátedra de Investigación de Innovación en 


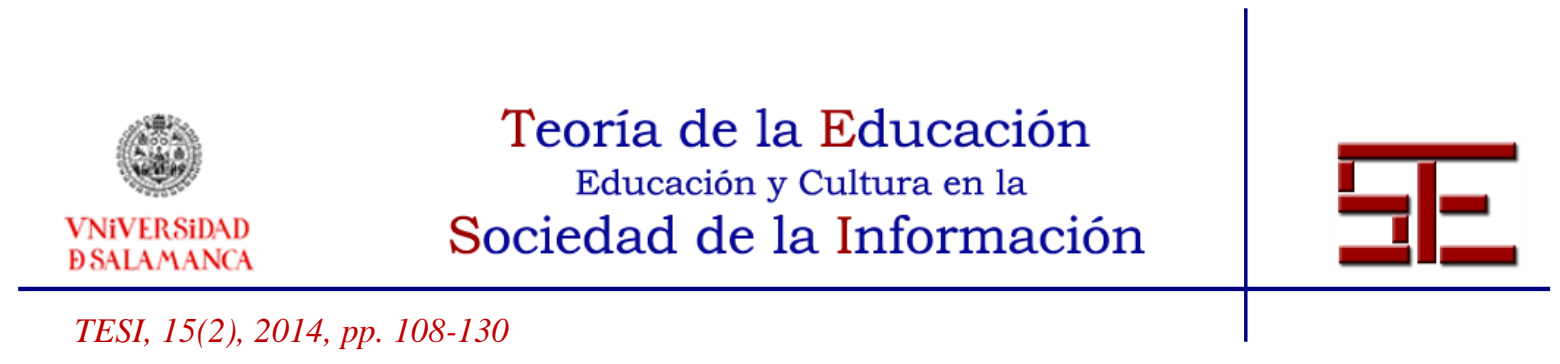

Tecnología y Educación del Tecnológico de Monterrey en: http://catedra.ruv.itesm.mx//handle/987654321/99.

(2) Validación de expertos:

Para la validación se proporcionó a los sujetos el acceso al OA y se les aplicó un cuestionario autoadministrado a través de survey monkey con cuestionamientos según su área. En cuanto a los cuestionarios dirigidos a especialistas, se tomó en cuenta a personas expertas en competencia comunicativa, pedagogía, tecnología y diseño gráfico y se aplicaron ocho cuestionarios. En este estudio, se retomó la segunda categoría de indicador definida por Giroux y Tremblay (2004), pues recae en las opiniones e intenciones que tienen los sujetos sobre los atributos o características de los OA y la importancia de la formación docente. El procedimiento que se siguió para establecer las categorías fue interpretar los constructos que se abordaron en la problemática y establecer las diferentes clases que se pueden establecer. Los constructos revisados tienen que ver con la competencia comunicativa que se pretende desarrollar a partir del OA y también con los atributos y propiedades de los Objetos de Aprendizaje que permiten su incorporación a la educación generando nuevos esquemas de aprendizaje.

(3)Aplicación en procesos de formación docente:

La investigación se basó en un estudio exploratorio a partir de una población homogénea de profesores, puesto que "cuanto más homogénea sea la población, menos necesidad tendrá la muestra de tener una precisión constante y ser de gran tamaño" (Giroux y Trembay, 2004, 111). Siguiendo la recomendación de Taylor y Bogdan (1997) se pensó como unidad de análisis la planta docente perteneciente a la categoría Profesor de Tiempo Completo de las carreras de Administración, Tecnología Ambiental, Tecnologías de la Información y Contaduría de la universidad objeto de estudio. Se procedió a definir la muestra, tomando los criterios de accesibilidad, disposición en tiempo, se optó por un subgrupo (profesores de tiempo completo) de la población de profesores del lugar donde se realizó dicho estudio. Los criterios que se tomaron en cuenta fueron: categoría, carrera donde imparten clases, cuatrimestre actual e infraestructura tecnológica. La muestra de 34 docentes seleccionada representa al personal con mayor antigüedad dentro de la institución. Más de la mitad son hombres de entre 33 y 60 años, 14 tienen el grado de maestro, de los cuales cuatro son del área tecnológica y los restantes son en educación. La mayoría es del área de ingenierías y los demás pertenecen al área de humanidades, todos tienen las mismas funciones docentes y administrativas.

En cuanto a la validez, Stake (2007) plantea que no sólo es necesario ser exacto en la medición de las cosas, sino también ser lógico en la interpretación del significado de

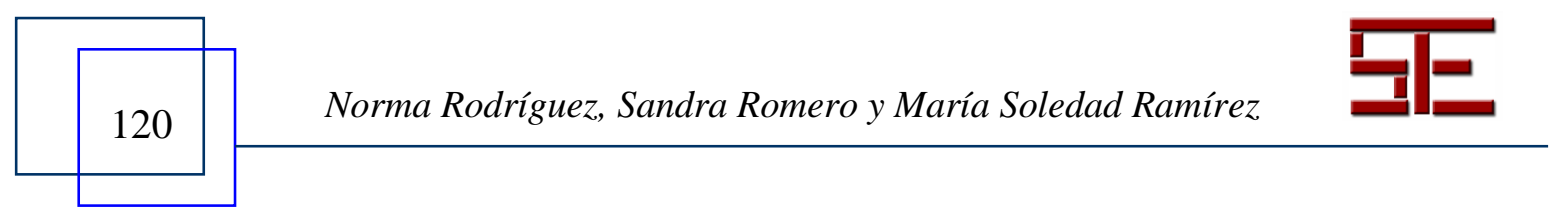




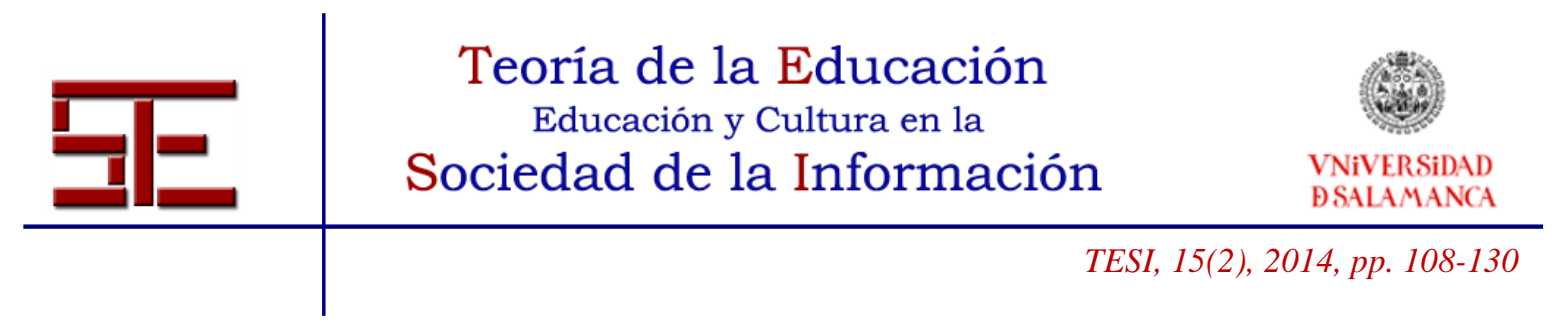

esas interpretaciones, por ello sugiere una triangulación de datos entre los hallazgos encontrados a través de las diversas fuentes de información con lo que nos indican otros estudios y teóricos que han abordado el mismo tema. En el estudio se hizo una triangulación de datos y de fuentes para dar validez a los datos colectados.

\section{4.- RESULTADOS}

Los resultados que dan cuenta sobre la competencia a desarrollar indican que más del $60 \%$ tanto de los docentes como de los expertos que interactuaron con el Objeto estuvieron convencidos de que sí es relevante el tema que se aborda, y que sí se amplía la competencia, mostrando cómo se puede enseñar a los alumnos. Más del $50 \%$ se manifestaron a favor de que sí se presenta cómo se puede medir el progreso en la competencia comunicativa a través de las estrategias de evaluación, cubriendo con ello los requisitos de relevancia y alcances.

Los puntos ligados a la estructura pedagógica indican que los objetivos de aprendizaje estuvieron definidos con claridad y que fueron adecuados a las intenciones didácticas que se perseguían al obtener un porcentaje en ambos indicadores de más del 50\%; sin embargo, el rubro de motivación mostró diferencias en percepciones porque ninguno de los usuarios ni de los expertos en contenido estuvieron completamente en desacuerdo en que el Objeto es altamente motivador, difiriendo de los pedagogos quienes el $20 \%$ estuvieron en desacuerdo en que fuera motivador y estimulara el interés de los alumnos. En cuanto a la evaluación, más del $50 \%$ de los participantes estuvieron de acuerdo en que si se exploran los conocimientos previos, el desarrollo de la competencia y que sí es útil la información que se proporciona en las retroalimentaciones.

La evaluación de la estructura tecnológica arrojó que más del $70 \%$ los participantes estuvieron completamente de acuerdo y de acuerdo en que es óptima la usabilidad del recurso sustentada en la navegación, la interfaz y el contenido. En cuanto a la accesibilidad, más del $57 \%$ de los participantes reconocieron que fue fácil acceder al portal donde se alojó el Objeto, además de que el diseño de los controles fue adecuado, estando de acuerdo más del $50 \%$. En el rubro de los elementos multimedia, la opinión estuvo dividida ya que más del $50 \%$ de las personas que interactuaron con el Objeto estuvieron de acuerdo en que se incluyeron elementos multimedia y $135 \%$ de los especialistas en contenido no concuerdan con lo anterior, por lo cual se infiere que es posible que exista una diferencia de conceptos sobre multimedia. En cuanto a si la herramienta se puede adaptar a dispositivos móviles, más del $45 \%$ de los especialistas estuvieron de acuerdo así como su uso en diferentes escenarios finalmente; el indicador de reusabilidad fue el mejor evaluado por los participantes. 


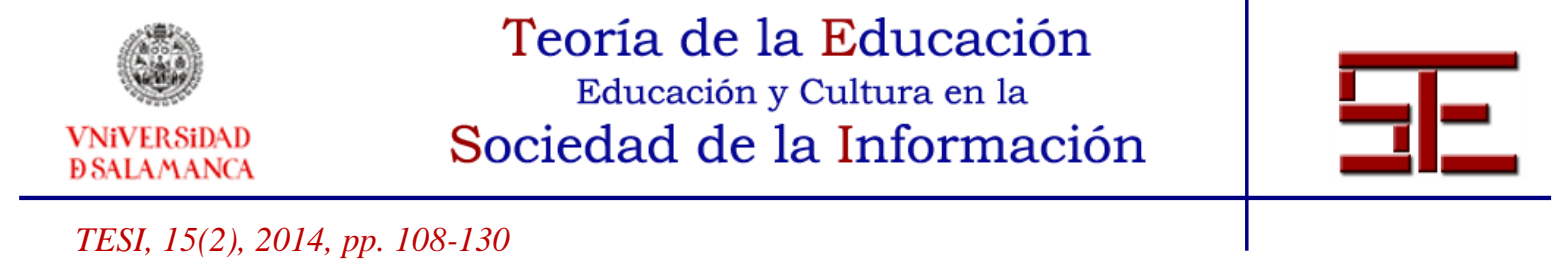

En cuanto a la evaluación de la categoría Lenguaje gráfico en sus indicadores de sintaxis gráfica y semántica del Objeto, arrojaron que la selección de la fuente, la tipografía, el diseño y la homogeneidad de las imágenes y su jerarquía visual son aceptables, toda vez que más del $40 \%$ de los participantes en el estudio estuvieron complemente de acuerdo en que los elementos mencionados y su combinación en el Objeto fueron los adecuados. En el rubro de semántica, más del $40 \%$ tanto de los usuarios como de los especialistas coincidieron en que el nivel lingüístico utilizado fue el apropiado para los usuarios, además de estar completamente de acuerdo en que hubo coherencia interna en el discurso y que la redacción fue clara, promoviendo así la comprensión del tema entre los usuarios.

En el rubro de aportaciones del Objeto en el desarrollo de la competencia saber comunicarse se identificó que los usuarios mostraron una mayor inclinación sobre la aplicación en el aula del tema, es decir, en el cómo mejorar la comunicación con los estudiantes y demás docentes, asimismo el reconocer otras formas de impartir clases a través de la mediación de la tecnología, y por sus comentarios se percibió que se estimuló para que buscaran implementar más elementos multimedia y algunas estrategias de aprendizaje que se proponen en el recurso. También identificaron algunas debilidades en la estructura pedagógica como fue la propuesta de usar más diagramas y gráficos en el recurso.

$\mathrm{Al}$ abordar el apartado de comentarios al OA se identificó que de acuerdo a los expertos en pedagogía, contenido, tecnología y diseño gráfico, las fortalezas más significativas detectadas en el recurso fueron la claridad de las instrucciones, la coherencia de los contenidos, la utilización de los scroll y la homogeneidad del diseño. En cuanto a las mejoras mencionaron: la redacción, los efectos multimedia, la navegación y las instrucciones de navegación. Y las propuestas para mejorarlo se tornaron en relación a las actividades, las imágenes, la estructura del mapa del sitio y la claridad en las instrucciones.

\section{5.- DISCUSIÓN Y CONCLUSIONES}

De acuerdo con los resultados obtenidos, se concibe que la temática manejada en el recurso fuera relevante, tanto para los usuarios como para los expertos, ya que las diversas fuentes coincidieron en que la competencia que se promueve es notable para una sociedad basada en el conocimiento acorde a las necesidades del propio individuo.

En cuanto a la planificación de los OA, es imprescindible que los propósitos no sólo indiquen el qué se quiere lograr, sino también deben estar sustentados en qué y para qué sé quieren alcanzar, justificando de esta manera por qué fueron configurados, convenciendo así al usuario de que se enriquecerá en conocimientos por medio del recurso. Esta idea prevaleció entre los participantes del estudio, puesto que opinaron que los objetivos de aprendizaje estuvieron definidos con claridad y que fueron adecuados a las intenciones didácticas que se perseguían. Chan, Galeana y Ramírez (2006) explican que un objeto de aprendizaje debe exponer en forma clara y precisa lo que se espera del

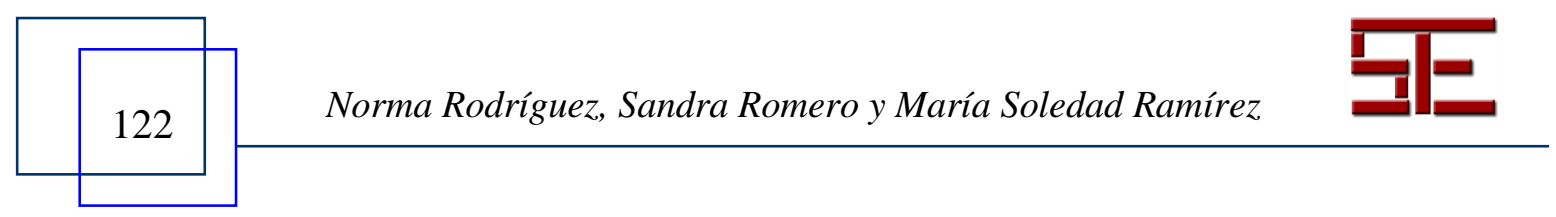




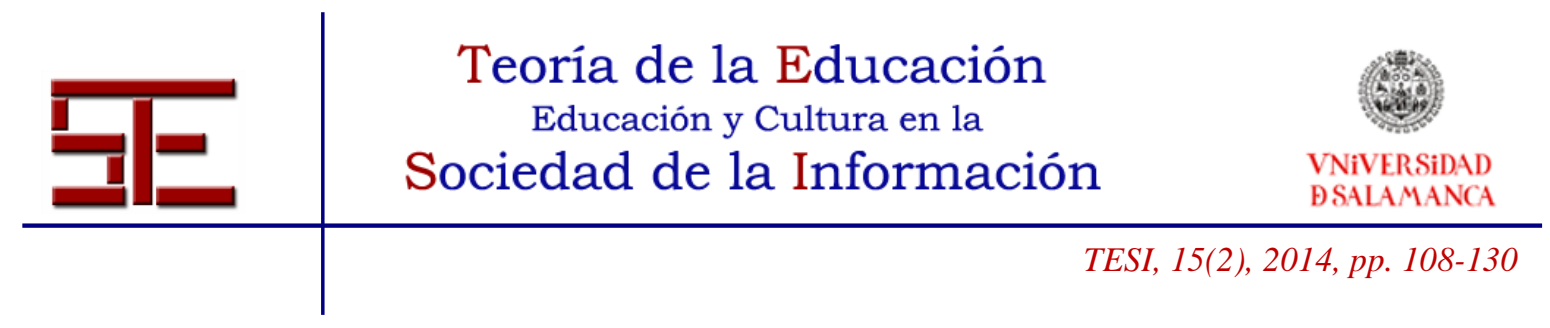

alumno cuando haga uso de éste. Por ello queda de manifiesto que la definición de los objetivos de aprendizaje es una parte elemental para el diseño instruccional ya que fomenta el aprendizaje significativo.

$\mathrm{El}$ aterrizar situaciones concretas con las que se identifiquen los usuarios de los OA permite propiciar el interés hacia los contenidos que se ofrecen en el recurso, una muestra fue lo que se reflejó en el indicador de motivación puesto que los participantes encontraron situaciones similares a su experiencia atrayendo su atención. A propósito, Wesley y Richard (2009) señalan que cuando el contenido se conceptualiza y aborda contextos representativos al grupo se incrementará la atención y motivación de los destinatarios de la información. Ello implica que sea imprescindible recrear escenarios familiares al usuario puesto que son elementos que lo estimulan a seguir interactuando con el recurso. Además de que el OA sea capaz de producir conocimiento y generar competencias basadas en las necesidades del estudiante (Rodríguez y otros, 2013).

Como muestra del desempeño de los sujetos de acuerdo con una competencia y con determinados productos se recurre a la medición del aprendizaje por medio de evaluaciones que exploran conocimientos previos y adquiridos a través de la interacción con el objeto. La mayoría de los docentes y expertos que consultaron el recurso estuvieron de acuerdo en que sí se exploraron los conocimientos previos y avance en el desarrollo de la competencia, catalogando como útil la información que se proporcionó en las retroalimentaciones.

La estructura tecnológica de un OA va más allá del aspecto técnico toda vez que su implementación sea accesible y adecuada para facilitar su consulta. La investigación arrojó que los expertos en tecnología fueron los que mejor evaluaron este rubro, ya que estuvieron completamente de acuerdo en que fue fácil acceder al Objeto, que la navegación fue amigable y que la interfaz era lógica para los usuarios, coincidiendo con lo que opinaron los docentes y expertos en pedagogía. Downes (2000) al igual que Chan y otros autores (2006) establecen que este tipo de instrumentos poseen la cualidad de la usabilidad ya que son ricos en recursos porque utilizan diferentes elementos tecnológicos atractivos sin perder su objetivo. Lo anterior supone que las personas que usan los OA buscan en ellos versatilidad tecnológica en sus componentes tales como la navegación e interfaz y en la medida en que se tengan más posibilidades de acceder a él, mayor impacto se tendrá.

Otra cualidad de este recurso tecnológico innovador es que tiene la ventaja de ser consultado desde diferentes dispositivos por su grado de adaptabilidad. Esta cualidad fue reconocida tanto por los expertos en tecnología como por los diseñadores gráficos, al expresar que el recurso sí se podía adaptar a tecnología móvil, lo cual ayuda a que se automatice más la información. Es decir que el OA debe generar conocimientos y entendimientos fructíferos y por ello debe poseer características propias que lo hagan singular en comparación con otros recursos digitales (Hoodgins, 2002). Por lo anterior se concibe que la peculiaridad de esta herramienta digital sea el ahorro de tiempo por su capacidad de gestión de información a través de ordenadores móviles, lo que permite su 


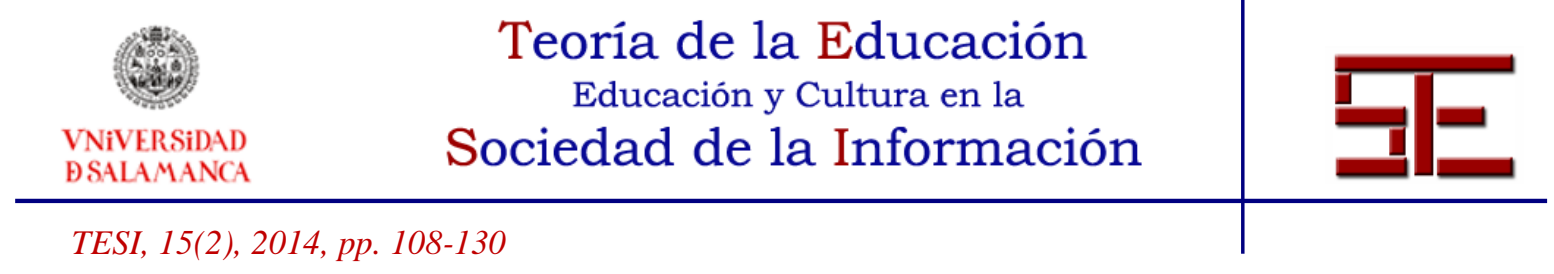

consulta de forma rápida sin que los usuarios se tengan que desplazar a lugares específicos para ello.

Los OA a pesar de que cubren necesidades específicas se pueden utilizar en diversos contextos y pueden ser comprendidos por personas de diferente preparación, es decir, si se aplica el recurso de reusabilidad. De lo anterior se deduce que los usuarios buscan herramientas que no sean desechables, sino que se puedan usar infinidad de veces, con diferentes personas y diversos escenarios, asimismo que se puedan combinar con otros elementos sin que se limiten sus cualidades, por ello, el uso de entidades informativas digitalizadas es una opción viable para apoyar los procesos de enseñanza aprendizaje independientemente del tipo de usuario o contexto.

Es importante que los elementos multimedia utilizados en el Objeto correspondan con la unidad temática del diseño, para que exista equilibrio entre cantidad y calidad. Chan, Galeana y Ramírez (2006) explican que los elementos multimedia articulados a los OA conforman un conjunto de bits de texto, gráfico, videos o audio. Es decir, van integrando conocimientos y recursos de multimedia en forma coherente, continua y secuenciada haciendo así más dinámica su interacción, sin embargo, hay que cuidar sus características tanto de diseño como de contenido porque de no ser así existe el peligro de que no apoyen el objetivo de aprendizaje trazado.

El fin de los metadatos es proporcionar información útil y descriptiva sobre el recurso de forma concatenada sin la necesidad de recorrer todo el OA para llegar a un tema de interés para el usuario, permitiendo así la interactividad. Los especialistas en tecnología indicaron que este rubro cumple con los requisitos puesto que son visibles y pertinentes en el recurso, cumpliendo con lo que recomiendan Rivera, Lozano y Ramírez (2008) y Wiley (2003) sobre el cuidado que hay que tener en el uso de los metadatos, ya que actualmente los diseñadores de los OA no han fortalecido este elemento. Por lo tanto, los metadatos ayudan a marcar pautas para que el usuario identifique puntualmente la forma en que está conformada la información y sea sencilla su consulta.

Los elementos de diseño también dotan de competencia al OA porque contribuyen satisfactoriamente a los objetivos de aprendizaje. Los resultados en la categoría de lenguaje gráfico y textual arrojaron que la selección de la fuente, el diseño, la homogeneidad de las imágenes y los colores utilizados lograron su cometido, porque su evaluación fue satisfactoria por parte de las personas que interactuaron con él, cumpliendo de esta forma con los estándares de diseño. Al respecto, Chan y otros autores (2006) explican que los estándares buscan abstraer fielmente situaciones prácticas del tema revisado y que es un punto relevante pues a falta de normas se puede caer en el error de que se inhiba el objetivo de aprendizaje. En consecuencia, se concibe que cuando se cubren los requisitos de diseño enmarcados en la sintaxis gráfica, se tiene la certeza de que contribuirá al cometido del recurso.

La articulación entre la coherencia del discurso y nivel linguí́stico debe corresponder con el usuario. Por los datos arrojados en el estudio, el requisito de

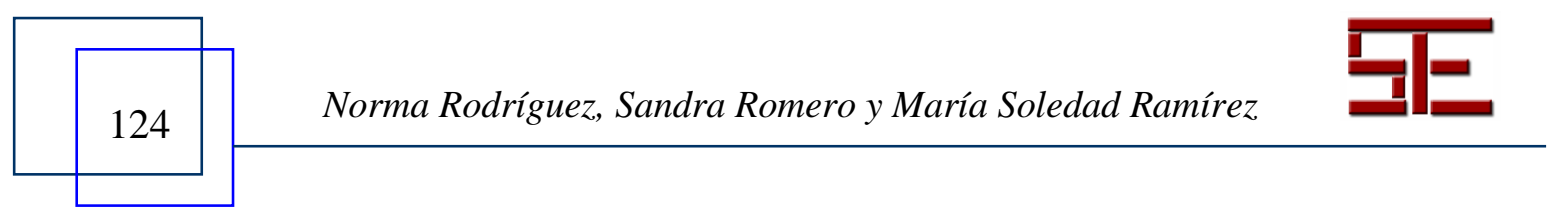




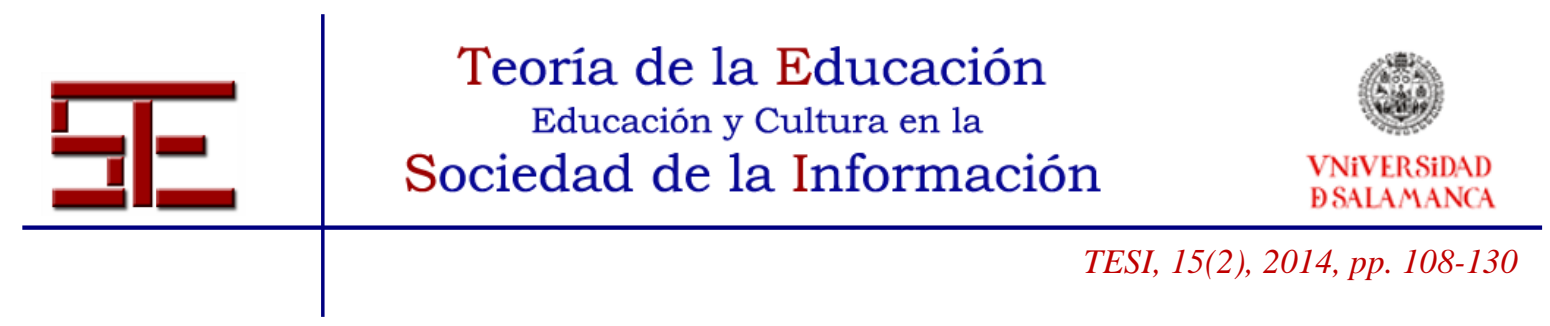

semántica se alcanzó puesto que los participantes coincidieron en que se cumple con los requisitos mencionados y por ende promueve la comprensión del tema. Retomando lo que establecen Amel, Defude, Duitama y Lecocq (2006) al dictar que la semántica es un rasgo que debe prevalecer entre los operadores de composición, contribuyendo con ello a que se alcance el objetivo del recurso además de que permite ser reutilizado o combinado con otros OA. Por lo tanto el Objeto que presenta reciprocidad entre el texto, el nivel linguíístico y el usuario podrá generar situaciones de aprendizaje significativas.

\subsection{Implicaciones para la práctica educativa}

La pregunta que guió el estudio fue: ¿Cuáles son los criterios de calidad que debe cubrir un objeto de aprendizaje (OA) orientado al desarrollo de sus competencias para saber comunicarse? Los datos colectados indicaron que los criterios de calidad de un $\mathrm{OA}$ son el manejo efectivo del contenido de la competencia a aprender, la equilibrada composición de su estructura pedagógica, la eficiencia en la estructura tecnológica y el correcto manejo del lenguaje gráfico y textual.

Por las cualidades mencionadas, el OA se muestra innovador frente a los recursos tradicionales de enseñanza en las prácticas educativas, puesto que este recurso es una herramienta para conocer nuevas formas de transmitir conocimientos y saberes, además de mantener y mejorar la motivación a través de los elementos multimedia que lo integran. Al respecto, Sánchez (2003) plantea que estas virtudes han sido vinculadas de forma general al implementar las nuevas tecnologías en el aula. Por lo tanto, la incorporación de los OA a la educación tiene bondades singulares, en comparación con herramientas como el administrador de presentaciones y el aula virtual, ya que el OA puede ser implementado sin importar las fronteras ni los tiempos, dado que cada usuario lo puede adaptar según sus necesidades o expectativas.

Se considera que los OA son herramientas recomendables para desarrollar competencias en los docentes a través de sus contenidos, puesto que se alcanza una conceptualización teórica debido a la consistencia de la información; la secuencia y distribución de cada uno de los temas que aborda son significativos para los docentes porque proporcionan y reafirman conocimientos y/o estrategias que pueden ser aplicados en su actividad en el aula para mejorar la interacción con los aprendices.

De esta manera, por los hallazgos de la investigación, se establece que el diseño de un OA articula elementos que lo confieren a ser una entidad digital que pueden ser utilizados, reutilizados o referenciados durante el aprendizaje apoyado con tecnología (Ramírez, 2006), además de favorecer el aprendizaje centrado en el alumno implementando estrategias constructivistas basadas en la solución de problemas (Ramírez, González, Lozano y Montalvo, 2005).

Es decir, al OA, al poseer bondades tecnológicas singulares (usable, reusable, relevante y accesible), se le considera como una nueva estrategia de aprendizaje mediada por la tecnología para transmitir conocimiento, sin importar las fronteras ni los 


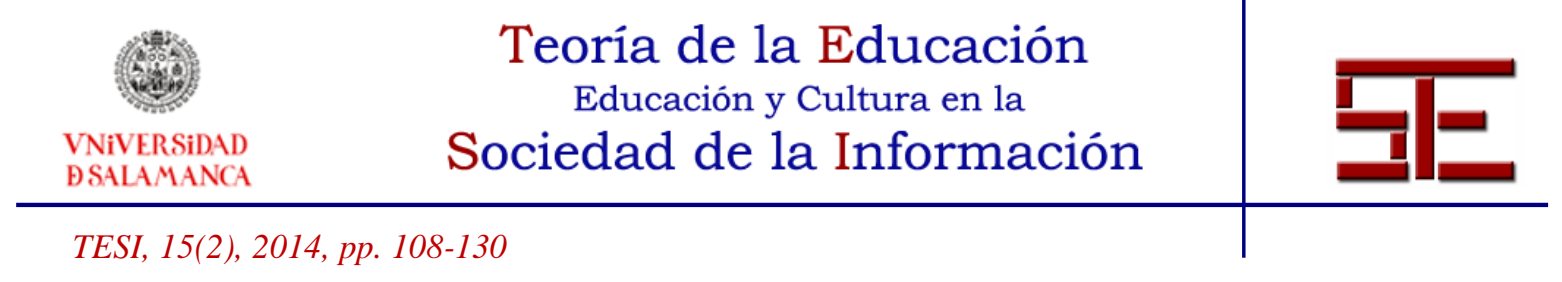

tiempos, dado que cada usuario lo puede adaptar según sus necesidades o expectativas, configurándolo como un nuevo tipo de elemento instruccional computarizado que surge del paradigma de modelamiento orientado a objetos.

Asimismo los objetos de aprendizaje son procesos inacabados susceptibles de ser mejorados conforme se va transformado el contexto donde se quiere intervenir, siempre y cuando no se dejen de lado los elementos que los dotan de calidad además de tener siempre presente el objetivo de aprendizaje por el cual fueron diseñados toda vez que el uso de herramientas tecnológicas sin interacción colaborativa no garantiza la construcción del conocimiento (Noguera, 2013).

Queda con este estudio una invitación a la exploración de nuevos recursos para las prácticas educativas y la formación docente, donde el desarrollo en sí de OA representa para el docente una forma de integrar los conocimientos que quiere transmitir y un tipo de recursos que puede ayudarle en la gestión de conocimientos.

\section{6.- BIBLIOGRAFÍA}

Abdón, M. (2003). Aprendizaje y desarrollo de competencias: competencias Magisterio. Bogotá, Colombia: Ecoe.

Aguilar, J., Moreno, L. M. \& Muñoz, J. (2004). Desarrollo de contenido educativo digital mediante objetos de aprendizaje. Memorias del XX Simposio Internacional de la Sociedad Mexicana de Computación en Educación (SOMECE). Recuperado el 22 de febrero, 2010 de

http://www.somece.org.mx/simposio2004/memorias/grupos/archivos/001.doc

Akpinar, Y. (2007). Liberating learning object design from the learning style of student instructional designers. Performance Improvement, 46 (10), 32-39. (ProQuest Education Journals. ID: 1613682191).

Amel B., Defude, B., Duitama, J. \& Lecocq, C. (2006). A Knowledge-Based Approach to Describe and Adapt Learning Objects. International Journal on ELearning, 5 (1), 95-102. (ProQuest Education Journals. ID: 986673131).

Appana, S. (2008). A Review of Benefits and Limitations of Online Learning in the Context of the Student, the Instructor, and the Tenured Faculty. International Journal on ELearning, 7 (1), 5-22. (ProQuest Education Journals. ID: 1428128531).

Argotte, L., Rodríguez, G. \& Paredes, J. (2009). Sistema aprend-e para la gestión de Objetos de Aprendizaje de apoyo a la operación de la CFE. Boletín del Instituto de Investigaciones Eléctricas, 12 (009) 37-44. Recuperado el 24 de febrero, 2010, de http://www.iie.org.mx/boletin012009/tec.

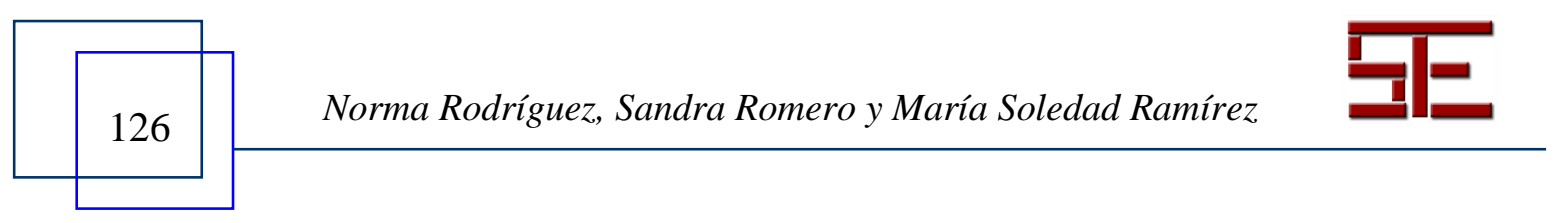




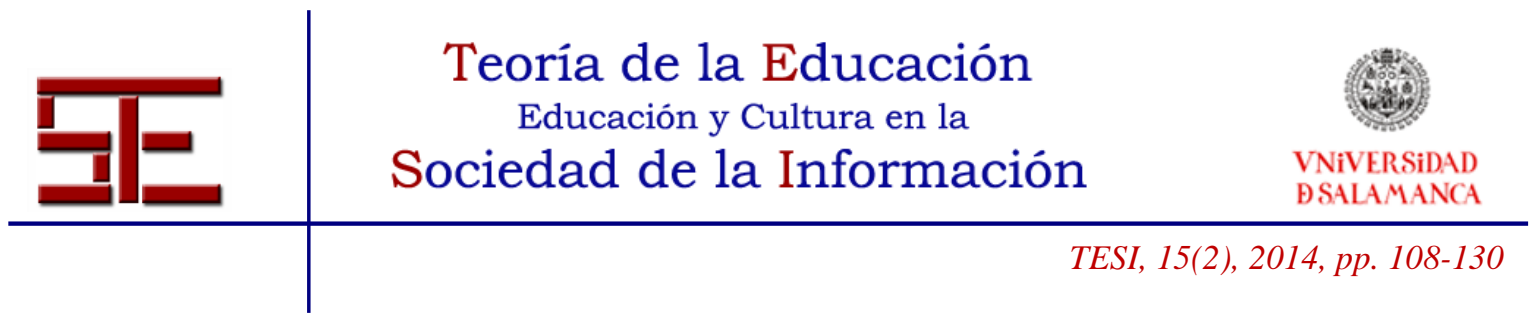

Banco Interamericano de Desarrollo (2002). La tecnología en América Latina y el Caribe. Recuperado el 25 de febrero, 2010, de

http://www.iadb.org/sds/doc/ResumenEduTecn.

Bates, A. \& Poole, G. (2003). Effective Teaching with technology in higher education.

San Francisco, EU: Jossey-Bass.

Cázares, L. y Cuevas, J. (2007). Planeación y Evaluación Basada en Competencias. México: Trillas.

Celaya, R., Lozano, F. G. \& Ramírez, M. S. (2009). Apropiación Tecnológica en los profesores que incorporan Recursos Educativos Abiertos (REA) en educación media superior. Memorias del X Congreso Nacional de Investigación Educativa. Veracruz, México.

Chan, M.E., Galeana, L. \& Ramírez, S. (2006). Objetos de Aprendizaje e Innovación Educativa. México: Trillas.

Chawla, S., y Singla, R.K. (2010). Mechanism for Learning Object retrieval supporting adaptivity. Journal of Telecommunications. Issue,2, 147-152.

Churchill, D. (2007). Towards a useful classification of learning objects. Educational Technology, Research and Development. (Proquest Document reproduction (ID $\mathrm{n}^{\circ}$ 23693).

De la Rosa, M.A. (2004). El desarrollo de competencias comunicativas: Uno de los principales retos en la educación superior a distancia. Memorias del Primer Congreso Virtual Latinoamericano de Educación a Distancia. Recuperado de http://www.ateneonline.net/datos/25_03_De_la_Rosa_Angeles.pdf

Downes, S. (2000). Learning Objects. Recuperado el 25 de febrero, 2010, de http://www.downes.ca/files/Learning_Objects.doc.

Elizondo, A., Paredes, F. \& Prieto, A. (2006). Enciclomedia un programa debate. Revista Mexicana de Investigación Educativa, 11 (28), 209-224.

Escamilla, G. (1998). Selección y Uso de Tecnología Educativa. México: Trillas.

Faulkner, L. (2009). Speak, listen, and connect. Rough Notes, 152 (7), 26-27. (ABI/INFORM Global. Document ID: 1803045391).

Fonseca, S. (2002). Comunicación oral. Fundamentos y práctica estratégica. México: Prentice Hall.

Giroux, S. \& Tremblay G. (2004). Metodologías de las Ciencias Humanas. La Investigación en Acción. México: Fondo de Cultura Económica.

Hargreaves, A. (2005). Profesorado, cultura y posmodernidad (Cambian los tiempos, cambia el profesorado). Madrid, España: Morata.

Hernández, J. L. \& Vázquez, J. (2004). Experiencia de la utilización de las TIC en procesos de formación pedagógica de tutores. Presentado en Primer Congreso Virtual Latinoamericano de Educación a Distancia. Recuperado de http://www.ateneonline.net/datos/45_03_Hern\%C3\%A1ndez_julieta. 


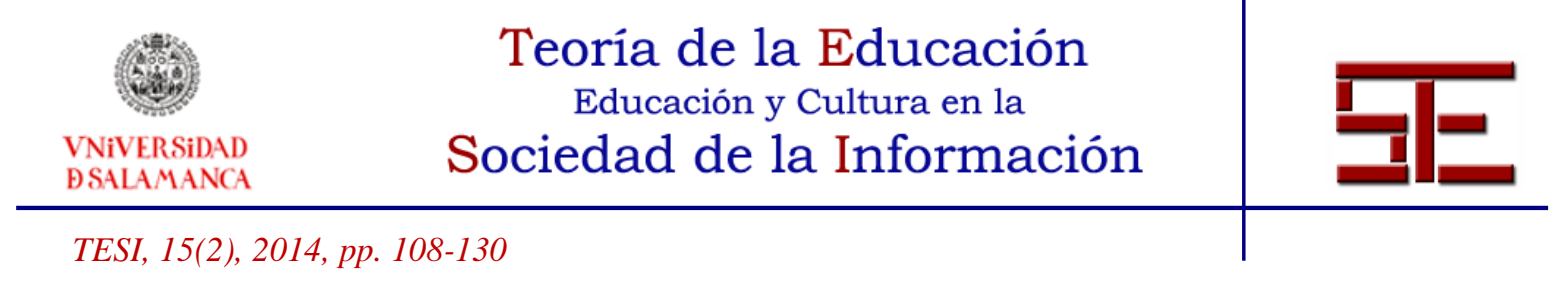

Hoodgins, H. W. (2002). The future of learning objects. En D.A Wiley (Ed.), The instruccional use of learning objects. Bloomington, IN: Association for Educational Communications and Technology. Recuperado de http://reusability.org/read/.

Ingo, D. (2006). A Metadata Profile to Establish the Context of Small LearningObjects: The Slicing Book Approach1. International Journal on ELearning, 5 (1), 59-66. (ProQuest Education Journals. ID: 986673111).

Jessup, S. (2007). Processes used by instructional designers to create e-learning and learning objects. (Abstract) (Proquest $\mathrm{n}^{\circ} 23693$ ).

Larbi, J. \& Moseley, J. (2009). Communication in performance-based training and instruction: from design to practice. (ABI/INFORM Global. Document ID: 1925705071).

Leal, D., \& Tibaná, G. (2006). Técnicas efectivas de búsqueda, evaluación y selección de Objetos de Aprendizaje. Recuperado el 25 de febrero, 2010, de http://www.diegoleal.org/docs/2006/Workshops/LEALTecnicasBusquedaOA.pdf.

Levinsen, K. T. (2007). Qualifying online teachers-communicative skills and their impact on e-learning quality. Education and Information Technologies, 12 (1), 41-51.

Looser, T. (2005). Fetch, plug, and play: How secondary science instructors use digital learning objects in their classrooms. (Proquest Document reproduction ID AAT 3350266).

Manny, E., Dagan, O., Tikochinski, B. \& Zorman, R. (2011). Using the Interactive White Board in Teaching and Learning - An Evaluation of the SMART CLASSROOM Pilot Project. Interdisciplinary Journal of E-Learning and Learning Objects, 7, 249-273.

Morin, E. (2008). Introducción al pensamiento complejo. Barcelona, España: Gedisa.

Noguera, I. (2013). Pedagogical directions to design and support collaborative knowledge building on-line tasks. Teoría de la Educación. Educación y Cultura en la Sociedad de la Información, 14 (1), 51-75.

Ogalde, I. \& González, M. (2008). Nuevas Tecnologías y Educación. México: Trillas.

Ossandón, A. \& Castillo, P. (2006). Design of learning objects propost. Revista de la Facultad de Ingeniería, 14 (1), 36-48. (Academic Research Library. Document ID:1065273341).

Paz, A. (2007). Manual imprescindible de Power Point. Barcelona, España: Anaya Multimedia.

Ramírez, M. S. (2006). El objeto del Objeto de Aprendizaje: Experiencia de colaboración institucional y multidisciplinar [Objeto de aprendizaje]. Disponible en la Escuela de Graduados en Educación de la Universidad Virtual del Tecnológico de Monterrey, en el sitio web:

http://www.ruv.itesm.mx/cursos/maestria/proyectos/oa/homedoc.htm.

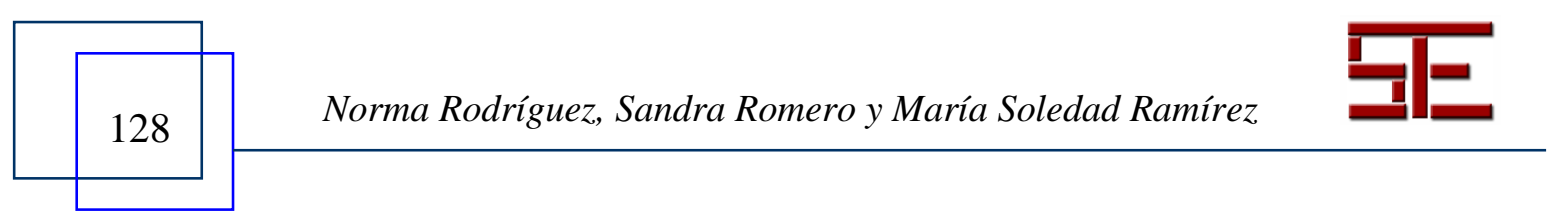




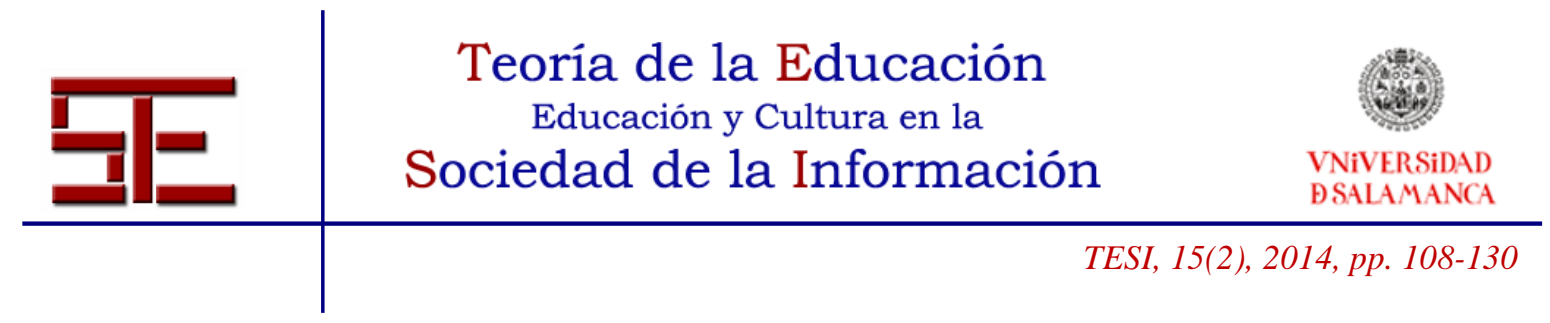

Ramírez, M. S. (2007a). Administración de objetos de aprendizaje en educación a distancia: experiencia de colaboración interinstitucional. En A. Lozano y V. Burgos, (Comps.) Tecnología educativa en un modelo de educación a distancia centrado en la persona. México: Limusa.

Ramírez, M. S. (2007b). Desarrollo de objetos de aprendizaje para ambientes constructivistas: estudios en una experiencia formativa en línea. En ICWE (Ed.), Libro de actas de la $7^{a}$ Conferencia Internacional de la Educación y la Formación basada en las Tecnologías. Barcelona, España: ICWE GmbH.

Ramírez, M. S. (2010). Conceptualizaciones teórico-prácticas de la enseñanza. En M. S. Ramírez (Coord.) Modelos de enseñanza y métodos de casos: estrategias para ambientes innovadores de aprendizaje (pp. 24-36). México: Trillas.

Ramírez, M. S., González, G., Lozano, F. \& Montalvo, D. E. (2005). Objetos de aprendizaje en educación a distancia: experiencias y reflexiones. Memorias del Simposio Internacional de Informática Educativa. Leira, Portugal.

Rivera, D. M., Lozano, F. G. \& Ramírez, M. S. (2008). El proceso de construcción de objetos de aprendizaje mediante cursos en línea: un estudio de casos múltiple. Memorias del XVII Encuentro Internacional de Educación a distancia. Guadalajara.

Rodríguez, P. A., Tabares V., Duque N. D \& Ovalle, D. A.(2013). BROA: An agentbased model recommend relevant Learning Objects from Repository Federations adapted to learner profile [version electrónica]. International Journal of Interactive Multimedia and Artificial Intelligence, 2, 6-11.

Rodríguez, N. E. (2010). Competencia saber comunicarse [objeto de aprendizaje]. Disponible en el sitio web: http://www.ruv.itesm.mx/convenio/tabasco/oas/sc/homedoc.htm. Disponible en el repositorio abierto de la Cátedra de Investigación de Innovación en Tecnología y Educación del Tecnológico de Monterrey en: http://catedra.ruv.itesm.mx//handle/987654321/99.

Sánchez, J. (2003). Producción de aplicaciones multimedia por docentes. Revista de Medios y Educación (021). (Redalyc Document reproduction Service $\mathrm{n}^{\circ} \mathrm{ED}$ 1655).

Santiago, J. A. (2004). Hacia la renovación de la práctica pedagógica en el trabajo escolar cotidiano. Educere, 9 (30), 1316-4910. Recuperado de http://www.scielo.org.ve/scielo.php?script=sci_arttext\&pid=S131649102005000300007\&lng=en\&nrm=iso\&ignore $=$. html.

Secretaría de Educación Pública (2009). Enciclomedia. Sitio oficial de la SEP. México: SEP. Consultado el 27 de febrero, 2010 de http://www.enciclomedia.edu.mx/Conoce_Enciclomedia/Que_es/Como_se_estruc tura.htm.

Selvi, K. (2010). Teacher's competencies. Cultural International Journal of Philosophy of Culture and Axiology, 7(1), 167-175. 


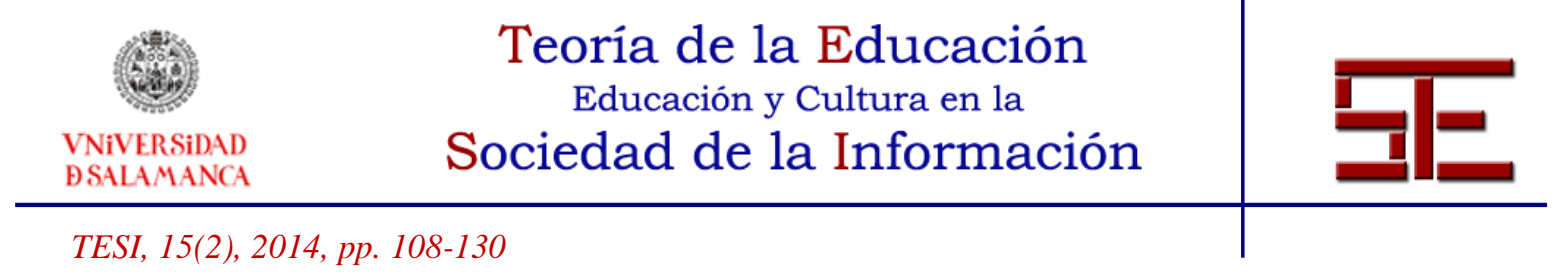

Stake, R. (2007). Investigación con estudios de casos. Madrid, España: Morata.

Taylor, S. \& Bogdan, S. (1997). Introducción a los métodos cualitativos de investigación. Madrid, España: Paidós.

Tejada, J. (2002). El docente universitario ante los nuevos escenarios: implicaciones para la innovación docente. Acción Pedagógica, 011 (2), 30-42. Recuperado de http://www.saber.ula.ve/handle/123456789/17162?mode=simple\&submit_simple $=$ Mostrar+el+registro+simple+del+art\%C3\%ADculo.

Wesley, H. \& Richard, P. (2009). Ideas prácticas para promover el aprendizaje activo y cooperativo: 27 maneras prácticas para mejorar la instrucción. Recuperado el 25 de febrero, 2010, del sitio web Temoa del ITESM en:

http://www.criticalthinking.org/resources/PDF/SP-Active_and_coop_learning.pdf.

Wiley, D. A. (2002). Learning object design and sequencing theory. Publicación doctoral. Recuperado el 25 de febrero, 2010 de http://opencontent.org/docs/dissertation.pdf.

Wiley, D. A. (2003). Connecting learning objects to instructional design theory: A definition, a metaphor, and a taxonomy. En D. A. Wiley (Ed.), The Instructional Use of Learning Objects: Online Version. Recuperado de: http://reusability.org/read/chapters/wiley.doc.

Reconocimientos: El artículo que aquí se presenta forma parte del Proyecto "Evaluar para mejorar: Sistema de evaluación educativa para escuelas de bajo logro académico", el cual fue financiado por el Fondo Mixto de Fomento a la Investigación Científica y Tecnológica CONACYT - Gobierno del Estado de Tabasco (TAB - 2008 - C13 94053). Participó también en este proyecto la Cátedra de Investigación de Innovación en Tecnología y Educación del Tecnológico de Monterrey (http://www.ruv.itesm.mx/convenio/catedra/). Los investigadores agradecemos el apoyo que se nos ha brindado para el desarrollo de este estudio y publicación.

Para citar el presente artículo puede utilizar la siguiente referencia:

Rodríguez Ramírez, N. E., Romero Corella, S, I. y Ramírez Montoya, M. S. (2014). Objeto de aprendizaje para la formación docente orientado al desarrollo de competencias de comunicación. Revista Teoría de la Educación: Educación y Cultura en la Sociedad de la Información. 15(2), 108-130 [Fecha de consulta: dd/mm/aaaa]. http://campus.usal.es/ revistas_trabajo/index.php/revistatesi/article/view/11889

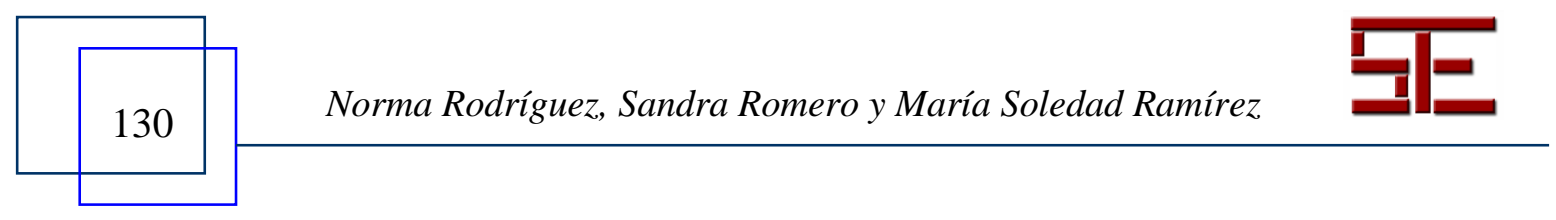

